NBER WORKING PAPER SERIES

\title{
CONSUMPTION RESPONSES TO IN-KIND TRANSFERS: EVIDENCE FROM THE INTRODUCTION OF THE FOOD STAMP PROGRAM
}

\author{
Hilary W. Hoynes \\ Diane Schanzenbach \\ Working Paper 13025 \\ http://www.nber.org/papers/w13025 \\ NATIONAL BUREAU OF ECONOMIC RESEARCH \\ 1050 Massachusetts Avenue \\ Cambridge, MA 02138 \\ April 2007
}

We are grateful to Bob Schoeni and Donna Nordquist for help with the PSID. We thank James Banks, Richard Blundell, Ken Chay, Steve Haider, Darren Lubotsky, Bob Lalonde, Doug Miller, Jim Ziliak and seminar participants at the UC Davis EJS Conference, the IRP Summer Workshop and the NBER Summer Institute as well as LSE, RWI Essen, SOLE, UCL, and ZEW for helpful comments. Alan Barreca, Peter Huckfeldt, Charles Stoecker and Rachel Henry Currans-Sheehan provided excellent research assistance and funding was received from the Joint Center for Poverty Research USDA Food Assistance and Nutrition Research Innovation and Development Grants in Economics Program. The views expressed herein are those of the author(s) and do not necessarily reflect the views of the National Bureau of Economic Research.

(C) 2007 by Hilary W. Hoynes and Diane Schanzenbach. All rights reserved. Short sections of text, not to exceed two paragraphs, may be quoted without explicit permission provided that full credit, including $\odot$ notice, is given to the source. 
Consumption Responses to In-Kind Transfers: Evidence from the Introduction of the Food

Stamp Program

Hilary W. Hoynes and Diane Schanzenbach

NBER Working Paper No. 13025

April 2007

JEL No. H31,I38

\begin{abstract}
Economists have strong theoretical predictions about how in-kind transfer programs -- such as providing vouchers for food -- impact consumption. Despite the prominence of the theory, there has been little empirical work documenting actual responses to in-kind transfers. In this work, we leverage previously underutilized variation in the date of the county-level original implementation of the Food Stamp Program in the 1960s and early 1970s. Using the Panel Study of Income Dynamics, we employ difference-in-difference methods to estimate the impact of program availability on food spending, labor supply and family income. Consistent with theoretical predictions, we find that the introduction of food stamps leads to a decrease in out of pocket food spending, an increase in overall food expenditures, and a decrease (although insignificant) in the propensity to take meals out. The results are quite precisely estimated for total food spending, with less precision in estimating the impacts on out of pocket food costs. We find evidence of small work disincentive impacts in the PSID, which is confirmed with an analysis of the 1960, 1970 and 1980 Census.
\end{abstract}

Hilary W. Hoynes

Department of Economics

University of California, Davis

One Shields Ave.

Davis, CA 95616-8578

and NBER

hwhoynes@ucdavis.edu

Diane Schanzenbach

Harris School

University of Chicago

1155 E. 60th Street

Chicago, IL 60637

schanzenbach@uchicago.edu 


\section{Introduction}

Providing assistance to the poor through in-kind transfers such as vouchers for food and housing garners more political support than providing assistance in cash. Supporters of such policies believe that providing voucher payments for certain goods (like groceries) will cause recipients to purchase more of the goods being subsidized, and that recipients will not be able to use public assistance to buy other, less socially desirable goods (like alcohol or cigarettes). According to canonical economic theory, though, providing a transfer in-kind should lead to the same outcome as a similar sized cash transfer as long as program participants are inframarginal. As a result, depending on consumer preferences the provision of in-kind transfers (relative to cash) may have little to no impact on purchases of the actual goods being subsidized.

Despite strong theoretical predictions about consumer behavior, little empirical evidence has been brought to bear on the impacts of providing in-kind transfers on consumer purchases. ${ }^{1}$ The Food Stamp Program (FSP) is one of the largest transfer programs for the low income population. In 2004, for example, the program cost $\$ 27$ billion and served 24 million persons. This compares to \$25 billion for Temporary Assistance for Needy Families and \$33 billion for the Earned Income Tax Credit. It has been very difficult for researchers to isolate the causal impact of the FSP on food spending, nutritional intake, labor supply and other outcomes. Because the program is national, there is not variation in program parameters (such as stark differences in state benefit levels or eligibility) that are typically exploited by researchers to measure program impacts. In the absence of programmatic variation, most researchers have studied the impact of the FSP by comparing food stamp recipients with eligible non-recipients. Since we would expect participants and nonparticipants to differ in important - and potentially unobservable - ways (Currie 2006) researchers

\footnotetext{
${ }^{1}$ There is a literature that explores the impact of cash transfer programs (Engen and Gruber 2001; Gruber 1997, 2000; Hubbard et al 1995; and Kantor and Fishback 1996) and in-kind transfer programs (Gruber and Yelowitz 1999) on consumption and wealth. This literature is particularly concerned with the insurance element in public programs and in estimating the impact on precautionary savings and consumption smoothing. More recently, Meyer and Sullivan (2004) examine the impact of welfare and tax reform on consumption, making the argument that consumption is an important measure of family well-being that has been largely ignored in the evaluation of transfer programs (Meyer and Sullivan 2003).
} 
have employed a variety of methods to control for selection into the program (see Fraker, 1990, for a comprehensive review the literature on food stamps and consumption).

In general, the literature has concluded that food stamps increase food purchase among program participants by a much larger amount than would be predicted by the canonical economic model. These studies have found that the marginal propensity to consume food out of food stamp income is about 4 times higher than it is out of cash income (Fraker 1990). As a result, food stamp benefits worth $\$ 100$ are thought to cause about a $\$ 17-\$ 47$ increase in food spending while a cash transfer of $\$ 100$ is associated with closer to a $\$ 5-\$ 10$ increase in food spending. But, as mentioned above, these results have been based on studies that rely on strong and untested assumptions. In addition, they are focused on the impact of the type of income, and only indirectly address the more basic policy question regarding the impact on food spending and other important outcomes of a sizeable, targeted transfer to the poor.

To measure the impact of the food stamp program in this project, we utilize an underexploited source of variation: the original introduction of the program across counties. ${ }^{2}$ There is tremendous variation in the timing of FSP introduction across counties in the United States-the earliest county programs were established in 1961 and the last county programs were established in 1975. The FSP started as eight county-level pilot programs and later expanded to 43 counties. This led to passage of the Food Stamp Act of 1964 which gave local areas the authority to start up FSPs in their county. This led to a steady increase in FSP adoption over the next ten years. Finally, the 1973 Amendments to the Food Stamp Act mandated that all counties offer FSP by 1975.

Our approach has the appeal of relying on non-marginal changes in incentives faced by consumers. This "program introduction" research design has been taken in recent analyses of other social programs such as Head Start (Ludwig and Miller 2007), Medicare (Finkelstein and McKnight 2005), and Title I (Cascio et al., 2006). It is also part of a larger literature examining impacts of the

\footnotetext{
${ }^{2}$ Currie and Moretti (2006) use food stamp program introduction across California counties to examine the impact of the program on birth outcomes.
} 
Great Society and Civil Rights era (for example see Almond, Chay and Greenstone 2006).

We use data from the Panel Study of Income Dynamics (PSID) to address two important research questions. First, we use the PSID from 1968-1978 to examine the impact of the FSP on food consumption. Specifically, we look at expenditures on food spent at home, meals out, food stamp savings, and total food spending. Second, we examine the FSP as a traditional income support program - a guaranteed benefit combined with a program phase-out or benefit reduction rate. This structure is well known to cause a disincentive to work (Moffitt 1983). While the benefit reduction rate in food stamps is quite low compared to cash welfare programs, standard labor supply models would predict that food stamps would reduce employment and hours worked. Here, we are able to augment our main estimates from the PSID with estimates based on the 1960, 1970 and 1980 decennial censuses.

We employ a basic difference-in-difference model where the treatment is at the county level, with controls for county and year fixed effects and state linear time trends. In this model, identification requires that there are no contemporaneous county level trends that are correlated with food stamp introduction and family economic outcomes. We control for possible confounders in two ways.

First, we examine the determinants of the food stamp program start dates across counties. We are guided by the historical descriptions of the political landscape around the FSP. Using county characteristics from the pre-treatment period, we find that earlier food stamp program introduction occurs in counties that are more populous, urban, black, low income, and with a smaller fraction of land used in agriculture. While these county characteristics are statistically significant determinants of county FSP implementation, we find that they explain little of the overall variation in food stamp implementation. However, ignoring these underlying determinants of county implementation could lead to spurious findings if counties that implement food stamps earlier are on a different trend than counties that implement later. Following Acemoglu, Autor and Lyle (2004), we use these results to 
motivate the inclusion of trends interacted with county pre-treatment characteristics in our regression models.

Second, food stamp introduction took place during a period of great expansion in programs for the poor in the United States. To control for the possible coincident expansion of other programs such as AFDC, Medicaid, Medicare, and social security, we include three measures of annual per capita county transfer payments (cash public assistance, medical care, and retirement and disability programs) obtained from Bureau of Economics Analysis Regional Economic Information System (U.S. Bureau of Economic Analysis 2007).

Overall, our results indicate that people behave as the theory predicts. We find that the introduction of food stamps leads to a decrease in out of pocket food spending, an increase in overall food expenditures, and a decrease in the propensity to eat meals out at restaurants. The results are quite precisely estimated for total food spending, with less precision in estimating the impacts on out of pocket food costs and meals out. Further, we find evidence that the marginal propensity to consume food out of food stamp income is close to the marginal propensity to consume out of cash income. The point estimates consistently point to small negative work disincentive effects, although few parameters are statistically significant. This is confirmed with an analysis of the 1960, 1970 and 1980 Census. The results are robust to many sensitivity tests including adding more fixed effects, examining subgroups of the sample, and placebo tests on groups not likely to use food stamps.

The remainder of the paper proceeds as follows. Section II presents a history of the food stamp program. Section III discusses the expected effects of the program and Section IV reviews the existing literature. Section V describes the data and Section VI presents the methodology. Sections VII and VIII present our results and Section IX concludes.

\section{Introduction of Food Stamp Program}

The origins of the modern Food Stamp Program began in 1961 with President Kennedy's 
first executive order establishing eight county-level pilot programs. ${ }^{3}$ The pilot programs were later expanded to 43 counties in 1962 and 1963 . The success with these pilot programs led to the Food Stamp Act of 1964 (FSA). The FSA gave local areas the authority to start up Food Stamp Programs (FSP) in their county. As with the current FSP, the program was federally funded and benefit levels did not vary across areas. In the period following the passage of the FSA, there was a steady stream of counties initiating food stamp programs. Support for requiring food stamp programs grew due to a national spotlight on hunger (Berry 1984). This interest culminated in passage of 1973 Amendments to the Food Stamp Act, which mandated that all counties offer FSP by 1975.

At the time the FSP was introduced and expanded, hunger and nutritional deficiencies were not uncommon among Americans. For example, a survey of low income families in Texas, Louisiana, Kentucky, and West Virginia in 1968-1970 found that 15 percent of whites and 37 percent of blacks had low hemoglobin levels (Eisinger 1998). There were also relatively high rates of deficiencies in vitamin $\mathrm{C}$, riboflavin and protein. In fact, a CBS documentary entitled "Hunger in America" which aired in 1968 raised national awareness of the problem and possibly influenced the policy debate on the FSP (Berry 1984).

It is important to understand the political context in which the FSP was introduced in the U.S. Prior to the modern day FSP, some counties provided food aid through the commodity distribution program (CDP). ${ }^{4}$ The main goal of the CDP was to support farm prices and farm income by removing surplus commodities from the market. It was seen, however, as inadequate to promote the nutritional well-being of low income persons and the Citizens' Board of Inquiry into Hunger and Malnutrition in the United States declared that "the commodity distribution program is a failure" in its 1968 report Hunger, U.S.A. (Citizen's Board of Inquiry 1968). Of the 1,000 poorest counties, onethird offered no food assistance of any kind in 1967. Furthermore, of counties that did offer the program, the commodities rarely reached a majority of the poor population because of obstacles such

\footnotetext{
${ }^{3}$ This section is based on Berry (1984) and MacDonald (1977).

${ }^{4}$ In 1967 - the only year that comprehensive county-level data is available -44 percent of the population lived in counties that offered the CDP.
} 
as distribution centers that were difficult to reach, the limited range of products and infrequent timing of the distribution of goods..$^{5}$ Consequently, debate about moving from the CDP to the FSP pitted powerful agricultural interests against advocates for the poor (MacDonald 1977, Berry 1984). In fact, as described in Berry (1984), passage of the 1964 Food Stamp Act was achieved through classic legislative logrolling. The farm interest coalition (Southern Democrats, Republicans) wanted to pass an important cotton-wheat subsidy bill while advocates for the poor (Northern Democrats) wanted to pass the FSA. Neither had majorities, yet they combined forces, supported each others bills, and both bills passed.

This political history is important because it illustrates that there was significant heterogeneity across the country in support for the FSP. Remember that the 1964 Act allowed for counties to voluntarily set up food stamp programs. The above discussion suggests that counties with strong support for farming interests may adopt FSP later in the period while those with strong support for the low income population may adopt FSP earlier in the period. Consequently, the food stamp program introduction may not be completely exogenous. We return to this below.

Figure 1 summarizes the overall pattern of FSP introduction. In particular, the figure plots the percent of counties offering FSP, where the counties are weighted by their 1970 population. Note this is not the food stamp caseload, but represents the percent of the national population that lived in an area offering a FSP. The figure shows that there was a long ramp up period between 1964 and 1975, leading to the eventual universal coverage of the FSP. For example in 1968 about half of the population lived in counties with FSP and by 1972 this rose to over 80 percent. It is this ramp up period that forms the basis of our research design. ${ }^{6}$

It is important to understand the CDP program in order to interpret the magnitude of the FSP effects. For example, if all food stamp recipients simply moved over from receiving an equal amount

\footnotetext{
${ }^{5}$ The boxes were also difficult to transport: the monthly box of food for a family of 4 weighed almost 95 pounds (Hunger U.S.A.).

${ }^{6}$ County FSP implementation dates are reported in USDA annual reports on county food stamp caseloads (U.S. Department of Agriculture, various years).
} 
of commodities, we would not expect to find any impact of the FSP on consumption. On the other hand, if counties adopting the FSP did not previously have access to the CDP or if the FSP provided a "larger" or "better" set of consumption choices, then the estimated coefficients would pick up the effect of the introduction of the program.

The evidence shows that the FSP indeed represents an important "treatment" over and above the CDP. First, as shown in Figure 2, the FSP caseload quickly overtakes the CDP caseload. In fact, the CDP was far from universally available prior to the FSP. For example, in 196735 percent of counties (not population-weighted) offered neither FSP nor CDP, 38 percent of counties offered only a CDP, 21 percent offered only a FSP, and 6 percent of counties offered both a CDP and FSP. ${ }^{7}$ Second, the CDP provided a very narrow set of commodities - the most frequently available commodities were flour, cornmeal, rice, dried milk, peanut butter and rolled wheat (Citizens' Board of Inquiry, 1968). In contrast, the food stamp benefits can be used to purchase all food items (except hot foods for immediate consumption, formula and vitamins). Further, the commodities were distributed infrequently. Finally, analyses of food intake in counties converting from CDP to FSP found that in its allowing participants to purchase a wide variety of food including fresh meat and vegetables, the FSP represented an important increase in the quality and quantity of food in comparison to the CDP (U.S. Congressional Budget Office 1977, Currie and Moretti 2006).

To get more insight into the geographic variation in the ramp-up to a universal FSP, Figure 3 shows the timing of food stamp introduction by county. In the figure, the shading of the counties is assigned by county FSP start up date - with darker shading denoting an earlier start up date. This shows a great deal of variation in FSP introduction within and across states. Our basic identification strategy uses this county level variation in food stamp "treatment."

To further explore the degree of within state variation in FSP start dates, Figure 4 presents FSP coverage rates by state for 1961-1975. This figure, as in Figure 1, plots the percent of the

\footnotetext{
${ }^{7}$ Theoretically, counties were not supposed to have both FSP and CDP in place at the same time, but in practice some places did offer both. We have not been able to find a consistent time series for county participation in the CDP. Consequently, we are unable to use this information in our empirical analysis.
} 
population (in this case in the state) that lives in a county offering food stamps. In some states, such as Nevada, Utah, Colorado, Massachusetts, and Florida, there was little or no within state variation in food stamp start dates. Other states such as California, New Mexico, and Minnesota have much greater within state variation in the food stamp start dates. The figure shows that in most states, the county level food stamp introduction took place in a narrower period than for the country as a whole.

As discussed above, the 1964 FSA allowed counties to start FSP—but it was voluntary. Therefore, for our research design to be valid, we need for the assignment of county start up of FSP to be exogenous. The discussion above suggests that northern, urban counties with large poor populations were more likely to adopt food stamp programs earlier while southern, rural counties with strong agricultural interests adopted food stamps later. This systematic variation in food stamp adoption could lead to spurious estimates of the program impact if those same county characteristics are associated with differential trends in the outcome variables.

To explore this we compiled characteristics of counties in 1960, on the eve of the first food stamp pilot programs. We use these "pre" characteristics to predict the date that the county adopted a food stamp program. The data on county characteristics come from the 1960 City and County Data Book, which is based on data from the 1960 Census of Population and 1960 Census of Agriculture. The dependent variable is the month and year of the county's food stamp start date- expressed as an index equal to 1 in January 1961, 2 in February 1961, and so on. In some specifications, we omit from the analysis the initial pilot counties as they were chosen by a different process than the later counties. In those cases, the dependent variable therefore ranges from 25 (January 1963) to 175 (July 1975). The independent variables include the percent of the 1960 population that lives in an urban area, is black, is less than 5, is 65 or over, has income less than $\$ 3,000$ (1959\$), the percent of land in the county that is farmland, and log of the county population. We include the population to capture the fact that large counties might find the application process less costly relative to the benefits of 
application. Descriptive statistics for this data are provided in Appendix Table $1 .{ }^{8}$

The results are presented in Table 1. We present estimates with (columns 2-4) and without (column 1) state fixed effects. All regressions are weighted by the 1960 county population. Focusing on the results with state fixed effects, we find that counties that are more populous, urban, black, and low income implement the FSP earlier. Further, those with a larger share of the population that is very young or old implement earlier and counties where more of the land is used in farming implement later. The impacts of county characteristics are smaller (in absolute value) in counties the South (column 4).

While these regression results show statistically significant impacts of the county characteristics on the timing of food stamp implementation, the quantitative importance of these predictors is small and most of the variation remains unexplained. To illustrate this, Figure 5 provides scatter plots of each of six county characteristics (x-axis) against the county FSP implementation date (y-axis). For guidance, we also provided the univariate linear regression line (weighted by the county population) for each panel. These figures show that the magnitude of the association between the county characteristics and the food stamp start date is weak and there is an enormous amount of variation that is not explained by the characteristics. This is consistent with the characterization of funding limits controlling the movement of counties off the waiting list to start up their FSP: "The program was quite in demand, as congressmen wanted to reap the good will and publicity that accompanied the opening of a new project. At this time there was always a long waiting list of counties that wanted to join the program. Only funding controlled the growth of the program as it expanded" (Berry 1984, p. 36-37).

We view the weakness of the fit of the model as a strength when it comes to our identification approach - in that much of the variation in the implementation of FSP appears to be

\footnotetext{
${ }^{8}$ Further, in this analysis - and in the subsequent analyses of the PSID and Census - we drop observations from Alaska due to inconsistencies in county definitions across samples and over time. Here we also drop very small counties (with population less than 1,000) because of missing data and a few counties where the percent of land used in farming was greater than 100 percent.
} 
idiosyncratic. Nonetheless, in order to control for possible differences in trends across counties that is spuriously correlated with the county treatment effect, we follow Acemoglu et al. (2004) and all of our regressions include interactions of these 1960 pre-treatment county characteristics with time trends. ${ }^{9}$

This period of FSP introduction took place as part of the much larger federal "war on poverty." For example, this period included the introduction of Medicaid, Medicare, Head Start and the Supplemental Nutrition Program for Women, Infants and Children (WIC). Further, AFDC, social security and disability income programs expanded. If these programs are mainly varying at the state level then our controls for state linear time trends or state-year fixed effects should absorb these program impacts. However, to control for the possible coincident expansion of other programs, we also include annual measures of county per capita transfer payments for cash income support, medical care, and retirement and disability programs. ${ }^{10}$

\section{Expected Effects of Food Stamp Introduction}

The current Food Stamp program provides a benefit to eligible families which is the difference between the cost of a family-size adjusted "thrifty food plan" (e.g. the guarantee in transfer program parlance) and the amount a family can afford to spend on food. In this scenario, as understood in the canonical Southworth (1945) model and illustrated in Figure 6, the original budget line reflects the tradeoff between food and all other goods, and is shifted out horizontally by the amount of food stamps received (labeled here as $B_{F}$ ). The basic prediction of this transfer is that overall spending on food and other goods will increase as shown by the illustrated optimal points $C_{0} *$ and $C_{1} *$ in the Figure 6(b). Out of pocket food expenses are expected to decrease (here the decrease is $F_{2}-F_{0}$ ). Consequently, the increase in food consumption, shown here as $F_{1}-F_{0}$, is less than the increase in food stamps $B_{F}$. It is possible, that a household that has a high demand for non-food

\footnotetext{
${ }^{9}$ Another approach might be to use these estimates to form propensity scores for matching counties. However, the weak fit of the model renders this less appealing.

${ }^{10}$ We have no documentation that any of these programs had the county roll out feature that provides the basis for our identification of the FSP. With respect to other nutrition programs, the National School Lunch Program had long been established, having started in 1946, and WIC was implemented more universally in 1972.
} 
relative to food might, as shown in Figure 6(c), might be constrained by the in kind nature of food stamps (relative to a cash transfer) and would locate at the kink. For these families, food stamps would lead to a larger increase in food consumption than an equivalent transfer in cash. ${ }^{11}$

Prior to 1979 (and during the time period studied here), families had to make a cash up front payment to receive the food stamp benefits. This feature, called the "purchase requirement" did not change the magnitude of the benefits a family received. ${ }^{12}$ Figure 7 shows the budget constraint in this case, where the amount of the purchase requirement is $P$. Note that the sloped part of the budget constraint is still shifted outward by the food stamp benefit (again $B_{F}$ ) but the top is censored and the attainable budget set is smaller. That is, a participant can no longer choose any consumption bundles that would have them spending more than their total income $(Y)$ minus $P .{ }^{13}$ This means that there will likely be more people consuming at the kink in the budget constraint under the purchase requirement program than under the current program. This suggests that in our analysis (when the purchase requirement was in place), the impact of food stamps on food spending will be somewhat larger than it would be under current (no purchase requirement) program or under a cash transfer scheme. $^{14}$

The focus of the paper is testing these predictions for consumption. The PSID provides several measures of food expenditures — cash outlays for food at home, food bought with food stamps and food away from home - that in theory respond in different manners to the food stamp program. ${ }^{15}$ Clearly food bought with food stamps should increase after the introduction of the program and cash

\footnotetext{
${ }^{11}$ Implicit in Figure 6 is the assumption that relative prices of food to nonfood are unchanged with the FSP. While it seems possible that the FSP could have led to increases in food prices (through increases in demand among the low income population) we have no data to test this hypothesis. As is typical in household survey data, in the PSID we measure expenditures not consumption.

${ }^{12}$ That is, if the family was deemed able to afford to spend $\$ 100$ on food, but the cost of the thrifty food plan was $\$ 300$, the family could purchase $\$ 300$ in food stamps for the cash price of $\$ 100$. Today, a similar family would receive simply receive $\$ 200$ in food stamps and would not have to outlay any cash.

${ }^{13}$ Of course, a potential recipient would choose not to participate in the program if they would prefer to consume such a bundle to the consumption bundle at the kinked part of the budget constraint.

${ }^{14}$ Beginning in 1971, participants could purchase their food stamp benefits in increments of $0.25,0.50,0.75,1.00$ of their full food stamp allotment (MacDonald 1977). They could make these purchases every 2 weeks. This "variable purchase option," as shown in Figure 7(c) will reduce the number of families at the kink.

${ }^{15}$ Food bought with food stamps is the value of food bought less the price paid for the stamps. So it is the "benefit" or "bonus value" from participating in food stamps.
} 
outlays for food at home should decrease. The prediction for spending on meals away from home is ambiguous given the positive income effect (due to the income transfer) and negative substitution effect (due to the reduction in the price of food at home). Given this low income population and high subsidy to food at home, we expect that the FSP will lead to a decrease in meals out. Finally, we expect an increase in total food consumed from all sources - deriving from higher total cash plus food stamp income under food stamps and the distortion of consumption toward food for those consuming at or near the kink point. Unfortunately, the PSID does not provide the data necessary to test the prediction that FSP leads to an increase in nonfood expenditures. ${ }^{16}$

We also estimate the impact of the FSP on labor supply and family cash income. Like other means-tested programs, the FSP alters the household's labor-leisure tradeoff increasing total income conditional on hours worked. In particular, the food stamp benefit is largest at zero hours of work, and benefits are reduced for each additional dollar earned (although at 30 percent the tax rate is much lower than typical tax rates under welfare programs). The combination of the income effect of the benefit as well as the substitution effect from the benefit reduction rate leads, unambiguously, to a predicted decline in employment, hours worked, and (if wages are fixed) earnings. In addition, family cash income (which as measured does not include food stamp benefits) would also be predicted to fall. We explore the possible work disincentives in the PSID by examining impacts on head's employment, annual hours, earnings, and family income. ${ }^{17}$

\section{Literature Review}

A large literature, mostly using data from more than 20 years ago, focuses on whether the FSP leads to larger increases in food spending than a similar sized cash transfer. However, the

\footnotetext{
${ }^{16}$ Depending on the year, the PSID sometimes includes expenditures on rent, utilities, tobacco and alcohol. Unfortunately, there are not enough years of data to implement our research design.

${ }^{17}$ Given the outward shift in the budget set and the expected increase in food consumption, we would also expect that the introduction of the FSP would lead to improvements in health. In an earlier version of the paper, we examined impacts on health outcome using the PSID variable on head's missed work due to illness. We concluded that this measure is too crude to capture any impacts as those models were very imprecisely estimated. Almond et al. (2006) estimate the impacts of the FSP on birth outcomes and infant mortality for the US as a whole and Currie and Moretti 2006 use natality data from California to examine impacts on birth outcomes.
} 
available variation that can be used to identify the impact is limited. Most of the observational studies in the literature (described in Fraker, 1990, and Levedahl, 1995) estimate the marginal propensity to consume food using the following linear specification:

$$
\text { fspend }_{i}=\beta_{0}+\beta_{1} \text { cash }_{i}+\beta_{2} \text { fstamp }_{i}+Z_{i} \gamma+\varepsilon_{i}
$$

where $f_{\text {spend }}$ is expenditure on food for household $i$, cash $_{i}$ and $f_{s t a m p}$ are income in cash and from food stamps, respectively, $Z_{i}$ is a vector of covariates such as household size and age/gender makeup, and $\varepsilon_{i}$ is a normal disturbance term. Variants on this standard specification include the “semi-log specification" which replaces cash with $\ln ($ cash) (food stamps, though, are typically still estimated in levels) or a "double-log specification" in which $\ln \left(f_{\text {spend }}\right)$ is the dependent variable. Here the primary impact of the food stamp program is measured as the increased consumption out of food stamps compared to cash income, as measured by the differences in estimated coefficients by income type in equation (1).

Fraker (1990), in a summary of the literature, reports that most of the food stamp literature finds that the marginal propensity to consume (MPC) food out of food stamps is 2-10 times higher than out of cash income and can easily reject the null hypothesis that $\beta_{2}=\beta_{1}$, even when the samples are restricted to only food stamp recipients who spend more on food than their food stamps are worth. The median study in Fraker's literature review reports a marginal propensity to consume food out of food stamp income that is 3.8 times as large as that from cash income. ${ }^{18}$ These findings are often interpreted as evidence that food stamps increase food spending by more than an equivalent cash-transfer system would.

The literature suffers from many of the standard shortcomings of observational studies. For example, most of the estimates were identified from differences between food stamp recipients and equally low-income families that were eligible for food stamps but for some unobservable reasons

\footnotetext{
${ }^{18}$ The MPC out of cash is estimated to be $0.03-0.17$ (with most estimates between 0.05 and 0.10 ), and the MPC out of food stamps is estimated to be $0.17-0.47$.
} 
chose not to enroll in the program (such as a preference to consume non-food goods). In this case, a comparison between participants and non-participants may overstate the impact of the program. Other studies compare food stamp recipients to higher-income families who are not eligible for food stamps. These studies rely strongly on the functional form imposed on income, which may fail to adequately account for the Engel curve which predicts that spending on food accounts for a larger share of total spending at very low levels of income. If the nonlinearities in food spending implied by the Engel curve coincide with income from food stamps, then the estimated coefficient on food stamp income could be biased (Whitmore 2002). Our identification strategy allows us to better isolate the impact of food stamps on spending.

Labor supply effects of the FSP have been studied by Fraker and Moffitt (1988), Hagstrom (1996), and Keane and Moffitt (1998). This prior literature, using more structural estimation methods, finds insignificant or small work disincentive impacts of the food stamp program. For example, Moffitt and Fraker find that the FSP reduces hours of work by participants by 1 hour per week, or since mean weekly hours worked for Food Stamp participants is about 9.5, a 9 percent reduction.

\section{Data}

The PSID is a panel data set collected by the Institute for Social Research (ISR) at the University of Michigan. The PSID began in 1968 with a sample of about 5,000 households containing 18,000 individuals, and subsequently all members (and descendants) of these original survey families were re-interviewed annually. The original 1968 sample consists of two subsamples: a nationally representative subsample of 3,000 households (Survey Research Center subsample) and a subsample of 1,900 households selected from an existing sample of low income and minority populations (Survey of Economic Opportunity subsample). To adjust for this nonrandom composition, the PSID includes weights designed to eliminate biases attributable to the oversampling of low income groups and to attrition. All results use the weights provided by the PSID. 
The central focus of the PSID is labor market and demographic variables, containing substantial detail on income, employment, and family composition. It also includes annual food (cash) expenditures for food consumed at home, away from home, and food purchased with food stamps (the value of food purchased less the purchase requirement). These data have been used by many researchers examining impacts of social programs on consumption (for example see Blundell and Pistaferri 2003, Gruber 1997, 2000, and Hubbard et al. 1995). In addition, we measure the head's employment status, annual hours worked, annual earnings, and total family income.

The public use release of the PSID includes state level identifiers for each year. In addition, we have obtained county level identifiers for each family in each year through special arrangement with the ISR.

We use data from interview years 1968 to 1978 . We stop the sample in 1978 so that our entire analysis period is before the end of the purchase requirement (which occurred in 1979). For our analysis of food consumption, we exclude interview years 1968 and 1973 (although we use all years 1968-1978 for the analysis of labor supply). We drop 1973 because the food consumption variables were not included in that survey and we drop 1968 because of inconsistencies in the definition of the food variables in that year. ${ }^{19}$ In our main estimates, we also trim observations with unusual values for food expenditures. In particular, we drop observations where the ratio of food spending to income exceeds 0.85 , where total annual food expenditures were less than $\$ 100$ (in 2005 dollars) or where annual family income was less than $\$ 500$ (in 2005 dollars). A test of sensitivity to these excluded observations is included in Table 8 .

There is some ambiguity in what time frame the food variables correspond to. In general, the

\footnotetext{
${ }^{19}$ In particular, the food stamp variable is measured more broadly as food assistance in 1968 and includes commodity distribution program, food stamp program, and other in-kind benefits. As a consequence, we find nontrivial food stamp (=food assistance) participation rates in 1968 in counties that do not as of yet have food stamp programs in place. Further, the cost of meals away from home is defined more broadly than in later years and the amounts are bracketed.
} 
survey is taken in spring and families are asked about "typical food consumption." ${ }^{20}$ The PSID then annualizes this measure and applies it to the prior calendar year. Nonetheless we assume, as other researchers have, that the food spending variables apply to this year (Blundell and Pistaferi 2003, Gruber 1997, 2000, Hubbard et al. 1995, and Zeldes 1989). All labor supply, earnings, and income variables correspond to the prior calendar year.

Unlike virtually all other U.S. public assistance programs there is no categorical eligibility for the food stamp program. That is, eligibility depends on income and asset tests but it is not targeted on particular demographic groups, such as single parents with children. Table 2 presents food stamp participation rates by education, family type and race based on the 1976-78 waves of the PSID. We use these years because all counties were participating in the program by 1976, but this period is prior to the elimination of the purchase requirement in $1979 .^{21}$ These tabulations show that while food stamp participation is highest among single parent families with children, the participation is widespread across all demographic groups. For example, among families where the head has less 12 years of education, 46 percent of single parent families with children, 14 percent of married couples with children, 14 percent of single nonelderly persons with no children, and 10 percent of single elderly participate in food stamps. The rates are uniformly higher among black families, with 56 percent of single nonelderly parent families with children (where the head has less than 12 years of education) participating in food stamps.

To take advantage of the universal nature of the FSP and to increase the power of our analysis, our base case model includes all families and singles headed by a nonelderly person. ${ }^{22}$ To capture their varying risks of being treated, however, in econometric model (below) we multiply the

\footnotetext{
${ }^{20}$ Specifically, spending on food at home and food out were first asked about "weekly" (1968-69), then for "last year" (1970-76), then finally settled into "annual spending" starting in 1976. Between 1968 and 1974 respondents were asked to report food stamp receipt "last year," but it is thought that most respondents answered about their current status. As a result, starting in 1975 the question was changed to inquire about food stamp receipt "last month."

${ }^{21}$ The participation rates are very similar when tabulated on the larger sample sizes of the Current Population Survey in 1980 (the first year in which food stamp information is available).

${ }^{22} \mathrm{We}$ limit the analysis to the nonelderly because of low take up rates among the elderly (Currie 2003, Haider et al. 2003). The results are qualitatively unchanged when we include the elderly.
} 
FSP treatment dummy by a group level food stamp participation rate (Bleakley 2007). Specifically, we use the 1976-78 PSID to calculate FSP participation rates by education $(<12,12,>12)$, race (white, nonwhite), marital status (married, not married) and presence of children (yes, no). We also present estimates for two sub-samples of the PSID_female headed households with children, and nonwhite female headed households with children. These samples are chosen because they are most likely to be impacted by the program.

Descriptive statistics for the consumption sample are presented in Appendix Table 2. There are a total of 39,623 (person-year) observations in the pooled sample, with 6,002 for all female heads and 4,501 for nonwhite female heads. All dollar amounts are in 2005 dollars and we use separate CPIs for food at home and food away from home. The descriptive statistics for the labor supply sample are presented in Appendix Table 3.

To augment our analysis of the work disincentive effects of the FSP, we also use the Decennial Census. The challenge is that our identification strategy relies on identifying counties which we need to assign the FSP treatment. The public release Census microdata, unfortunately, do not include county identifiers. We instead use county level tabulations of the full census which the Census Department releases as separate data products. We use these STF (summary tape file) data to construct county panels for 1960,1970 , and 1980. The limitation of this data is that we can only use the variables that have been released with the data and that are consistently available over the three censuses. The outcome variables we examine include: male and female labor force participation rates and the percent of families with family income in excess $\$ 10,000$ (in 1979 dollars). These are aggregate county outcomes and can not be refined for groups most likely to be impacted by the FSP. $^{23}$

\footnotetext{
${ }^{23}$ The smallest geographic area identified in the census micro data is the county group. We also estimated models using the 1970 and 1980 public use micro data IPUMS data (there is no microdata for 1960). The advantage of using the IPUMS is that we can construct the variables we would like for the treatment groups we like. However, we have to aggregate the FSP treatment across all counties in the country group. Further, we had to combine county groups to accommodate the changing county group boundaries between the 1970 and 1980 Census. In the end, this aggregation was substantial and the results had very low power. The results are available on request.
} 
We merge the PSID and Census data using the county identifiers, with 1960 county characteristics (from the City and County Data Book), annual per capita county transfers (from the BEA) and the FSP policy variables (from the USDA).

\section{Methodology}

Our data discussed above consists of household level data with geographic indicators that span the period during which the FSP is introduced. By pooling periods, we can control for area and time fixed effects. This helps to address the concerns arising from the voluntary nature of the FSP introduction across counties.

Although our identification strategy is based on a person's county of residence, the probability of being impacted by the program varies widely across people within a county. Program participation varies widely with education, race and family type as shown in Table 2. To account for this variation in program participation, we multiply the food stamp treatment variable-which varies at the county-by-year level-by a group specific FSP participation rate. This approach has been used in other recent studies such as Banarjee et al. (2007) and Bleakley (2007). In particular, we estimate the following model where the unit of observation is the family-year:

$$
y_{i c t}=\alpha+\delta F S P_{c t} P_{g}+X_{i t} \beta+\gamma_{1} Z_{c 60} * t+\gamma_{2} T P_{c t}+\theta_{g}+\theta_{g} * t+\eta_{c}+\lambda_{t}+\varepsilon_{i c t}
$$

where $y_{i c t}$ is the outcome variable, $F S P_{c t}$ is an indicator variable equal to 1 if county $c$ in year $t$ has a FSP program, $X_{i t}$ are family characteristics, $Z_{c 60}$ are 1960 county characteristics, $T P_{c t}$ are per capita county transfer income variables, $\eta_{c}$ are county fixed effects and $\lambda_{t}$ are time fixed effects. (We estimate additional specifications with state linear time trends and state-year fixed effects.) $P_{g}$ is the group ( $g$ ) specific food stamp participation rate; we use 24 groups defined by race (white, nonwhite), marital status (married, not married), presence of children (yes, no), and education $(<12,12,>12)$. We also include fixed effects for each group and for group interacted with linear time.

The individual controls $X$ include controls for education, race, urban location, state unemployment rate, and for the food consumption models the log of family cash income. As 
suggested by Currie (2003), $X$ includes a full set of fixed effects for the number of children and number of adults in the family to control nonparametrically for the differences in food needs across families. All estimates are weighted using the PSID family weight and the standard errors are clustered on county.

We also present estimates that limit the sample to groups that had high participation rates: unmarried women with children, and the further subset of nonwhite unmarried mothers. In this case, we do not interact the FSP variable with $P_{g}$ as in equation (2), and instead estimate the following model:

$$
y_{i c t}=\alpha+\delta F S P_{c t}+X_{i t} \beta+\gamma_{1} Z_{c 60} * t+\gamma_{2} T P_{c t}+\eta_{c}+\lambda_{t}+\varepsilon_{i c t}
$$

where all variables are defined as above. These sample restrictions reduce the number of available observations by more than 80 percent, and generally provide less precise estimates.

In addition, a series of placebo tests are presented in Table 7. These are estimated using the specification in equation (3), but the sample is limited to groups that have low FSP participation rates such as high education married couples with children.

As described above, the food variables in the PSID measure expenditures as of the interview which is fielded in spring of each year. Thus $t$ in (2) and (3) above refers to the interview year. Given this timing, we set the treatment variable $F S P_{c t}$ to 1 if county $c$ has a FSP program in place by January of year $t$. When examining the labor supply and income, the variables refer to the calendar year prior to the interview year. In that case, $t$ refers to the year prior to the interview year and we define the treatment variable to be 1 if county $c$ has a FSP in place by January of the year prior to the interview year. $^{24}$

We include the pre-treatment county variables $\left(Z_{c 60}\right)$ interacted with linear time trends to control for the observable determinants of county food stamp adoption (Table 1). The variables in $Z$

\footnotetext{
${ }^{24}$ There is some evidence (Berry 1984) that it took some time to ramp up the new county FSP programs. We have explored the sensitivity to lagging the treatment effects and while the specific estimates change somewhat, the results are qualitatively similar.
} 
include the log of the population, the percent of land in farming and the percent of population black, urban, age less than five, age greater than 65 and with income less than $\$ 3,000$ each interacted with a linear time trend. We include the county transfer variables $T P_{c t}$ to control for the possible coincident expansions of other transfer programs during this period. In particular, we include three per capita annual county transfer income variables: (1) retirement and disability programs, (2) medical care (Medicare, Medicare, and military health care), and (2) cash public assistance (AFDC, SSI, and general assistance).

\section{Results for Expenditures on Food}

We begin with the overall pooled sample and the estimation approach described in equation (2). To reflect differing probabilities of being affected by the program, we interact the treatment dummy with a group specific FSP participation rate. Note that with this interaction, the parameter estimates represent impacts for families that take up the program (e.g. no post-estimation scaling needs to be done). The main results, presented in Table 3, provide estimates for three outcome variables: the log of real expenditures on food at home, a dummy for any meals out, and the log of real total food expenditures. Expenditures on food at home includes all cash spending on groceries, but does not include cash outlay for food stamps or the value of food purchased with stamps. The meals out variable is equal to one if a household reports spending any money on meals out in a typical week. About three quarters of the pooled sample and only about one-half of single mother families report any spending on meals out (Appendix Table 2). Finally, total food expenditures includes money spent on food at home, food out, and also includes food purchased with food stamps and the value of any other free meals or food that the household received.

We present five specifications. The first specification includes demographics, the 1960 county characteristics interacted with linear time, and year and county fixed effects. In the second specification we add state linear time trends. In the third we add the per capita county transfer income variables. In the fourth, we adopt the basic Engel curve specification and control for the log 
of family (cash) income. We postpone concerns about the possible endogeneity of this variable (due to work disincentive impacts of the food stamp program) to the next section. In the final specification, we replace the state linear time trends with state-year fixed effects.

The first panel finds — as predicted by the theory — a small, negative impact of food stamps on out-of-pocket (cash) spending on food at home. The second panel shows - as expected - a reduction in purchase of meals out measured as whether a family reports eating any meals out in the past year. Both of these findings are imprecisely measured, however, and not statistically significant. Finally, in the third panel, FSP is associated with a statistically significant and robust 18 percent increase in total expenditures on food. Overall, the results in Table 3 are consistent with the theoretical predictions but not always statistically significantly so.

In this double-log specification, the coefficient on log of real family cash income (not reported in the table) estimates a elasticity of food spending with respect to income of 0.30 and evaluating at means implies a marginal propensity to consume food out of cash income of 0.09 . This is quite consistent with the existing literature (summarized above).

The results show that adding the controls for the county transfer income (column 3), family income (column 4), or including state-by-year fixed effects (column 5) improve precision and the overall fit of the model, but make little difference for the parameter estimates.

Table 4 presents the impact of the program on a sample limited to female-headed households with children. In this case, the first panel displays the impact of the introduction of the program in one's county on an individual's likelihood of receiving any food stamps. The results show consistently that the introduction of the food stamp program leads to increases in food stamp receipt (as expected). We can interpret the coefficient as the effective participation rate. Note that these implied participation rates are somewhat lower than those implied in Table 2 and may be due to a program ramp up period taking place. Panels B through D present impacts of the program on food spending at home, meals out, and total food spending. To scale up the results to be per food stamp 
family, the numbers in italics divide the parameter estimates by the sample mean food stamp participation. ${ }^{25}$ As with the pooled results in Table 3, the results for female headed households show that the introduction of the FSP leads to a large statistically significant increase in total food expenditures. Again, we have no statistically significant results for meals out or out of pocket spending on food. Interestingly, the magnitude of the results for total food from the targeted sample is quite similar to the pooled sample in Table 3. For example, Table 3 shows an 18 percent increase in total food expenditures with the introduction of the FSP compared to $26-28$ percent in the sample of female heads of household (after scaling up by sample participation rate).

Table 5 further narrows the sample to include only nonwhite female headed households with children. The results are broadly consistent with the earlier results for the overall sample—negative and insignificant impacts on meals out and cash expenditures on food at home and positive impacts on total food - but are typically smaller and less precisely estimated. The overall impact on total food expenditures is more muted in this sample, with a 6-13 percent increase (after scaling up by sample participation rate).

In Tables 4 and 5, as well as Table 3, the results are quite consistent across the specifications. For the remainder of the paper, we adopt as our base specification the specification in column (4) with state linear time trends, county transfers, and log of family income.

Policy analysts have long been interested in the impact of an additional dollar's worth of income on food spending, and whether the marginal propensity to consume (MPC) food varies out of cash income versus food stamp income. One can make a further adjustment of these estimates to calculate how the predicted increase in total food expenses compares to the increase in food stamp benefits. Table 6 presents the estimates of the MPC out of both types of income. These MPCs are derived from the estimates on treatment dummy and on $\log ($ income) in the model of the log of total food expenditures. All estimates come from the specification in column (4) of Tables 3-5, with

\footnotetext{
${ }^{25}$ As with the earlier use of food stamp participation rates, here we calculate the mean food stamp participation rate using interview years 1976-1978 representing the period after all counties have adopted the program and before the purchase requirement is eliminated.
} 
controls for county transfer income and state linear time trends. The MPCs are evaluated at the mean values of food spending and income levels among food stamp recipients. The results in row (1), based on the pooled sample, indicate an MPC for food out of food stamp income equal to 0.16 and an MPC for food out of cash income of 0.09. In subsequent rows, we present parameter estimates and implied MPCs for subgroups with higher probabilities of being impacted by the FSP. ${ }^{26}$ Consistent with the Engel curve relationship, as the sample becomes more disadvantaged, the MPC food out of cash income increases although not dramatically. For example, the MPC food out of cash income rises from 0.086 in the full sample to 0.111 in the sample restricted to families with income less than or equal to $\$ 25,000$ (in 2005 dollars). The MPC food out of food stamps also increases as the sample becomes more disadvantaged (we will return to this below). ${ }^{27}$

Returning to the estimates for the full sample in row (1), the results are consistent with the theoretical predictions - the MPC food out of food stamps is quite close to the MPC food out of cash income. This would suggest that most households are inframarginal. This is in stark contrast to the existing literature that finds the MPC food out of food stamps to be 2-10 times larger than the MPC food out of cash income. The difference between our results and the previous literature comes fully from our lower estimate of MPC food out of food stamp income, which we feel is the result of our credible research design. Our estimate of the MPC food out of cash income is estimated from crosssectional variation in cash income - similar to the rest of the literature - and is similar in magnitude to the older literature.

While close in magnitude (and certainly much closer than the prior literature suggested), we are still finding that the estimated MPC food out of in-kind transfers (at 0.16) is larger than the MPC food out of cash income at (0.09). Thus far, we have maintained that the only reason for a higher

\footnotetext{
${ }^{26}$ Estimates in rows (1)-(6) use the pooled model specification in equation (2), and in particular the treatment dummy is interacted with a group FSP participation rate. Thus the parameter estimates reflect impacts for a treated person. In rows (7)-(8), there is no interaction with the FSP participation rate. The numbers in italics scale up the parameters by dividing by the sample FSP participation rate as described in the presentation of Table 4. The MPCs are directly comparable across samples.

${ }^{27}$ As described above, our estimated MPC food out of food stamps is likely to be larger than it would be if our data corresponded to a period without a purchase requirement.
} 
MPC food out of food stamps compared to the MPC food out of cash income is that households are constrained by the in-kind nature of the program (as illustrated in Figure 6c). There are, however, other reasons why the MPCs may differ. The family member with control over food stamp benefits may be different from the person that controls earnings and other cash income. If the person with control over food stamps has greater preferences for food, then we may find that the MPC food out of food stamps is higher than the MPC food out of cash income. Alternatively, it is possible that the inkind transfer sets a mental target for how much a family "should" spend on food, and as a result alters a family's preferences toward consuming at the budget kink point. Finally, families may perceive that food stamp benefits are a more permanent source of income compared to earnings.

Returning to Table 6, we find that as the sample becomes more disadvantaged (cutting on income, education, or race) the MPC food out of food stamps rises relative to the MPC food out of cash income, suggesting that more of the lowest-income households are located at the kink. This is to be expected, as the budget constraint is shifted out further for lower-income families because the absolute level of food stamp transfers is higher for the poorest families. If preferences are constant between the higher and lower income groups, it is straightforward to show that a larger shift out in the budget set will lead to a greater likelihood of locating at the kink for the more disadvantaged sample. Whitmore (2002) found a similar result when comparing responses to food stamp programs in Alabama and San Diego. Overall, however, while the ratio of the MPCs rises at the highest (for the sample of nonwhite nonelderly families) to 3.7 , most of our estimates imply the ratio is 2.5 or lower.

One should be cautious in interpreting these "marginal" calculations for food stamp income because of the nonmarginal nature of the research design - i.e. the design compares spending when there was no program to spending after the program was introduced. On the other hand, the MPC for income is identified off of cross-sectional variation in cash income, and is subject to the usual criticisms of this type of identification.

\section{$\underline{\text { Sensitivity Checks }}$}


We conducted many specification tests. First, in Table 7 we present placebo tests - that is, we estimate the models for groups that are not expected to be impacted by the food stamp program. In these and all other specification tests, we use the model with state linear time trends and controls for county per capita transfers and $\log ($ family cash income). We estimate the models for high income (more than \$50,000 in 2005 dollars) families, high income married couples with children, and white high educated (college educated or more) families with children. The results, as expected, show no significant impacts of the FSP on food consumption for any of these groups. In fact, here the point estimates on our most robustly estimated outcome — total food expenditures - while small is negative compared to the consistently positive estimates for the likely impacted groups.

Further specification testing is provided in Tables 8 and 9. We present the specification tests for the pooled sample of all nonelderly in the PSID, with the treatment dummy interacted with the group specific FS participation rate. (The results are qualitatively the same for the female headed sample and the nonwhite female headed sample.) Panel A of Table 8 presents estimates where we drop all observations with minor or major imputations to the food variables. Imputations represent about one to five percent of observations depending on the variable. Panel B of Table 8 presents estimates where we add back in the observations that were trimmed from the original dataset because of unusual food consumption data. The results change little with these changes in sample.

In panel $\mathrm{C}$ of Table 8 we test for policy endogeneity by adding a one year lead of the county FSP implementation. If this were statistically significant, that would suggest that there were underlying trends in food consumption that are correlated with the county FSP adoption leading to spurious estimated impacts of FSP. The coefficients on the policy lead variables are small and often opposite-signed compared to the actual policy variable. ${ }^{28}$

Table 9 explores the sensitivity of the results to the particular functional form specified.

\footnotetext{
${ }^{28}$ In results not presented here, we also explored whether the treatment effect varies over time by adding an interaction between the treatment effect and a dummy for 1973 or later. Time varying treatments might result because the early adopting counties were more enthusiastic about the program than the counties that were forced into compliance. However, we find no evidence of differences over time. We also estimated models adding back in the 1968 data. The results, while changing somewhat, provide the same qualitative conclusions.
} 
Column (1) of the top panel restates the main results of the paper found in column (4) from Table 3, estimated as the log of food spending on the availability of the food stamp program along with the log of income. Subsequent columns experiment with including food spending and cash income in levels, and including a quadratic in income. To compare the results across specifications, the implied MPCs out of food stamp and cash income are reported at the bottom of the table. The results of the introduction of the food stamp program are similar across specifications, although allowing less curvature in the relationship between cash income and food spending tends to reduce the MPC out of income. The bottom panel repeats the exercise, limiting the sample to those with relatively low levels of family income. The estimated MPCs out of food stamp income are larger among the more targeted group compared to the top panel, and the estimated impact of the program is quite robust across specifications.

As discussed earlier, the expansion of the food stamp program took place during a time of great change in the U.S. system of government support. We address this by controlling for the county level transfer variables. Another, more direct approach, is to examine the impact of the FSP on family government transfer income. In particular, with the PSID we can measure income of the head and wife from AFDC, other welfare income (SSI, General Assistance), and social security. The results of that exercise, presented in Table 10, show no significant impact of the FSP on other sources of income support.

In sum, the results in this section show that the food stamp program is associated with increases in total food consumption and (less consistently) decreases in out of pocket food spending. The results are robust to including state linear time trends, state-year fixed effects, and do not appear to be the result of other program expansions during this time period.

\section{Results for Work Disincentive Effects}

The FSP has the structure of an income support program. A family is eligible for a given level of food stamps ("the guarantee") which decreases as earnings increase. The combination of the 
income effect of the benefit as well as the substitution effect from the benefit reduction rate leads, unambiguously, to a predicted decline in employment, hours worked, and (if wages are fixed) earnings. In addition, family income - which as measured here as cash income and does not include food stamp benefits - is also expected to fall. It is important to establish whether there are work disincentives of the program because the impacts of a reduction in earnings may offset gains in additional food consumption. The prior literature, which is based mostly on structural estimation, finds little or no impact of the FSP on labor supply. Here we take a very different approach by using the introduction of food stamps.

PSID results for the full nonelderly sample, as well as female heads and nonwhite female heads (paralleling Tables 3-5) are presented in Table 11. As above, the parameter estimates in the pooled models reflect impacts for a "treated" family. For the female headed household samples, we provide in italics the equivalent scaled estimates (which are equal to the parameter estimates divided by the sample FSP participation rate). We present estimates for whether the head worked at all last year, the head's annual hours last year, the head's annual earnings last year, and the total family income. Note that hours and earnings are unconditional measures - that is, they include nonworkers. ${ }^{29}$ Thus any impact on hours or earnings will reflect both intensive and extensive labor margins.

Across all outcomes and all three samples, each of the point estimates is consistent with the theoretical predictions of decreases in employment, hours, earnings and income. However, few estimates are statistically significant. There is a large, statistically significant decrease in whether the head reports any work in the pooled sample, and annual hours worked in the female heads and nonwhite female heads samples are estimated to decline significantly with food stamp implementation. The results for annual hours worked suggest a reduction of 12 to 16 percent. We also examine the impacts on labor supply using decennial Census data. The only public

\footnotetext{
${ }^{29}$ Family income is specified in log form. Because they include zeros, the head's earnings are specified in levels.
} 
use release of the Census that identifies the county of residence is county-level aggregate filesknown as the STF files. Using that data, we estimate models of labor force participation rates for all females and males (aged 16 and over), and all females with a child under age six. Lastly, we can examine the propensity to have family income in excess of 10,000 in real 1979 dollars. We estimate models similar to those presented above, with decade fixed effects replacing the year fixed effects. Because the observations are at the county-year level, we do not include any demographic characteristics and the regression is weighted using the county population. As above, standard errors are clustered on county. The results are presented in Table 12-with panel A reporting estimates for all persons and panel B reporting estimates for nonwhites (for variables that are available).

It is important to note that these treatment groups are broader than the targeted samples used in the PSID and there is no way to weight the treatment by group participation rate (as in our pooled sample) because the data are county wide averages. With that said, the results show a relatively statistically precise, small negative estimated work disincentive effect. For example, the estimate for males shows that implementing a food stamp program leads to a statistically significant 0.003 decrease in the labor force participation rate compared to the mean value of 0.76 . In addition, the probability that overall family cash income (not including food stamps) is less than $\$ 10,000$ per year (in 1979 dollars) increases by a statistically significant 1-3 percentage points.

Together, these results suggest that there is a small, negative impact on income and work associated with the food stamp program. The relative modest size of these effects is perhaps not surprising given the low (for income support programs) benefit reduction rate of $30 \%$ in the food stamp program. In the AFDC/TANF program where the work disincentive effects are estimated to be much larger (Moffitt 1992) the benefit reduction rate is closer to 100 percent. However, as a check and to gauge the magnitude of the expected labor supply effects of the food stamp program, we simulated the impact of the program on annual hours worked in our PSID sample using estimated labor supply elasticities from the Negative Income Tax experiments (Robins and West 1983). These 
simulations show that the food stamp program is expected to lead to about a 100 hour reduction in annual hours worked among our female heads of household sample (compared to our estimate of a 165 hour reduction in Table 11). Note that the simulations predict only the intensive margin effect, and are therefore expected to be below our estimates which capture the extensive and intensive margin impacts. The simulations for the full or pooled sample predicted a 30 hour reduction in hours, which scaled up by the group FS participation rate represents about a 350 hour reduction in hours somewhat larger than our (insignificant) estimated 229 reduction in Table 11. Overall, we take this as a useful exercise which corroborates our estimates of modest work incentive effects in the food stamp program. ${ }^{30}$

\section{Conclusion}

In this paper we present evidence on the effect of the largest near-cash transfer program food stamps - on the consumption and labor supply of the poor. The overall program effects of the Food Stamp Program have been difficult for researchers to isolate, because there is little cross-state or over-time program variation to exploit. Here we use county-level variation in the original adoption of the program from 1963-1975 to identify the impact of food stamps. Using the PSID and Census data, we find that the FSP significantly increases food consumption, and causes a small negative impact on work behavior of the poor. By introducing and developing this research design, the paper provides an important contribution to the literature on evaluating the behavioral impacts of transfer programs.

Perhaps more importantly, the paper tests the economics of in-kind transfers. Economic theory has strong predictions about how consumers will reallocate their spending in response to inkind transfers. Despite the well known theoretical predictions, there has been relatively little

\footnotetext{
${ }^{30}$ More specifically, we assign the compensated wage and income effects based on family type (female headed households are assigned the effects for "single females" and all male headed singles/families are assigned the effects for "husbands"). We assign maximum food stamp benefits and the food stamp breakeven income level by family size using the 1975 food stamp parameters in Table 2.2 from MacDonald (1977). We assume no nonlinear response to the implementation of food stamps and therefore simulate the change in hours for those families with head's earnings below the food stamps breakeven point. Full results of simulation available on request.
} 
empirical work to test those predictions. We find that the poor react to in-kind transfers by reducing their out-of-pocket spending on the targeted good, just as theory predicts. But total consumption of the targeted good from all sources - cash outlays and in-kind transfers - increases. Additionally we find that, consistent with theory, providing the food stamp benefits in voucher form leads to a minimal distortion of the consumption choice relative to what it would be if the benefit were provided in cash. This is in stark contrast to the findings in the existing literature, which use data and methods from more than two decades ago.

Our findings, then, contribute to the literature in two distinct ways. First, we provide important and new estimates of the impact of the food stamp program on consumption and labor supply using a credible research design. Second, we test predictions of the theory of consumer choice and in particular the differential impacts of cash versus in kind transfers.

Even though there have been changes in the population of the United States and the parameters of the Food Stamp Program since the period we are studying, these results are relevant for today's policy debates. To date, there have been no studies that we have found that provide credible evidence on the impact of the FSP on consumption and income. The FSP is once again receiving considerable political attention, and it is crucial from a policy maker's perspective to be able to measure the benefits of the program not only on food spending, but also on other outcomes like income, child well-being, and health. 


\section{References}

Acemoglu, Daron, David Autor and David Lyle. 2004. "Women War and Wages: The Impact of Female Labor Supply on the Wage Structure at Mid-Century." Journal of Political Economy, 112(3), June, $497-551$.

Almond. Doug, Kenneth Chay and Michael Greenstone (2006). "Civil Rights, the War on Poverty, and Black-White Convergence in Infant Mortality in Mississippi."

Almond et al. (2006). "The Impact of the Food Stamp Program on Infant Outcomes."

Banerjee, Abhijit, Esther Duflo, Gilles Postel-Vinay, and Tim Watts. 2007. "Long Run Health Impacts of Income Shocks: Wine and Phylloxera in 19th Century France," working paper.

Berry, Jeffrey M. (1984). Feeding Hungry People: Rulemaking in the Food Stamp Program. New Brunswick, NJ: Rutgers University Press.

Bleakley, Hoyt (2007). "Disease and Development: Evidence from Hookworm Eradication in the American South," Quarterly Journal of Economics 122(1): 73-117.

Blundell, Richard and Luigi Pistaferri (2003). "Income Volatility and Household Consumption: The Impact of Food Assistance Programs.” Journal of Human Resources, Volume 36.

Cascio, Elizabeth, Nora Gordon, Ethan Lewis, and Sarah Reber (2006). "Fiscal Responses to the Introduction of Title I."

Citizens’ Board of Inquiry (1968). Hunger, U.S.A. Boston: Beacon Press.

Currie, Janet (2003). "U.S. Food and Nutrition Programs," in Means-Tested Transfer Programs in the United States, Robert Moffitt (ed.). Chicago: University of Chicago Press.

Currie, Janet (2006). "The Take-up of Social Benefits," in Alan Auerbach, David Card, and John Quigley (eds.) Poverty, the Distribution of Income, and Public Policy. New York: Russell Sage Foundation.

Currie, Janet and Enrico Moretti (2006). "Did the Introduction of Food Stamps Affect Birth Outcomes in California?" Paper prepared for the National Poverty Center conference Health Effects of Non-Health Policy.

Eisinger, Peter (1998). Toward an End to Hunger. Brookings Institution Press, Washington DC.

Engen, Eric and Jonathan Gruber (2001). "Unemployment Insurance and Precautionary Saving." Journal of Monetary Economics, 47(3), June 2001, 545-579.

Finklestein, Amy and Robin McKnight (2005) "What Did Medicare Do (And Was It Worth It)?" NBER Working Paper 11609. September 2005.

Fraker, Thomas (1990). "Effects of Food Stamps on Food Consumption: A Review of the Literature." Washington, DC: Mathematica Policy Research, Inc. 
Fraker, Thomas and Robert Moffitt (1988). "The Effect of Food Stamps on Labor Supply: A Bivariate Selection Model," Journal of Public Economics, February.

Gruber, Jonathan (1997). "The Consumption Smoothing Benefits of Unemployment Insurance," The American Economic Review, Vol. 87, No. 1. (Mar., 1997), pp. 192-205.

Gruber, Jonathan (2000). "Cash Welfare as a Consumption Smoothing Mechanism for Single Mothers," Journal of Public Economics, 75(2), February 2000, 157-182.

Gruber, Jonathan and Aaron Yelowitz (1999). "Public Health Insurance and Private Savings," Journal of Political Economy, 107(6): 1249-1274.

Hagstrom, Paul (1996). "The Food Stamp Participation and Labor Supply of Married Couples: An Empirical Analysis of Joint Decisions." Journal of Human Resources 31(2):383-403.

Haider, Steven J., Alison Jacknowitz, Robert F. Schoeni. 2003. "Food Stamps and the Elderly : Why is Participation So Low?” Journal of Human Resources, 38 (supplement): 1080-1111.

Hubbard, R.G. J. Skinner and S.P. Zeldes (1995) "Precautionary Saving and Social Insurance" Journal of Political Economy 103:360-399.

Kantor, Shawn and Price Fishback (1995). 'Did Workers Pay for the Passage of Workers' Compensation Laws?” Quarterly Journal of Economics 110: 713-42.

Keane, M. and R. Moffitt (1998). "A Structural Model of Multiple Welfare Program Participation and Labor Supply.” International Economic Review, 39:3, 553-589.

Levedahl, J. (1995): "A Theoretical and Empirical Evaluation of the Functional Forms Used to Estimate the Food Expenditure Equation of Food Stamp Recipients", American Journal of Agriculture Economics, 77 (November): 960-968.

Ludwig, Jens and Douglas Miller (2007) "Does Head Start improve children's outcomes? Evidence from a regression discontinuity design.” Quarterly Journal of Economics 122(1): 159-208.

MacDonald, Maurice 1977. Food, Stamps, and Income Maintenance. Institute for Poverty Research Press: Madison, WI.

Meyer, Bruce and James Sullivan (2003) "Measuring the Well-Being of the Poor Using Income and Consumption”, Journal of Human Resources, 38: 1180-1220.

Meyer, Bruce and James Sullivan (2004) "The Effects of Welfare and Tax Reform: The Material Well-Being of Single Mothers in the 1980s and 1990s" Journal of Public Economics, 88:1387-1420.

Moffitt, Robert (1983). “An economic model of welfare stigma.” American Economic Review 73(5):1023-1035.

Moffitt, Robert (1992). "Incentive Effects of the U.S. Welfare System: A Review." Journal of Economic Literature 30(1):1-61. 
Robins, Philip and Richard West (1983) "Labor Supply Response." In Final Report of the Seattle/Denver Income Maintenance Experiment, edited by SRI International. Vol 1:pp91-198. Washington DC: US GPO.

Southworth, H.M. (1945). "The Economics of Public Measures to Subsidize Food Consumption." Journal of Farm Economics, February 27: pp. 38-66.

U.S. Bureau of Economic Analysis (2007). "Regional Economic Accounts," http://www.bea.gov/bea/regional/reis/

U.S. Department of Agriculture, Food and Nutrition Service (various years). "Food Stamp Program, Year-End Participation and Bonus Coupons Issues."

U.S. Congressional Budget Office (1977). "The Food Stamp Program: Income or Food Supplementation?” Washington, U.S. Government Printing Office.

Whitmore, Diane (2002). "Using the Food Stamp Cash-out to Test Intra-Household Bargaining," mimeo.

Zeldes, Stephen (1989). "Consumption and Liquidity Constraints: An Empirical Investigation." Journal of Political Economy, 97: 305-346. 
Figure 1: Cumulative Percent of Counties with Food Stamp Program, 1960-1975

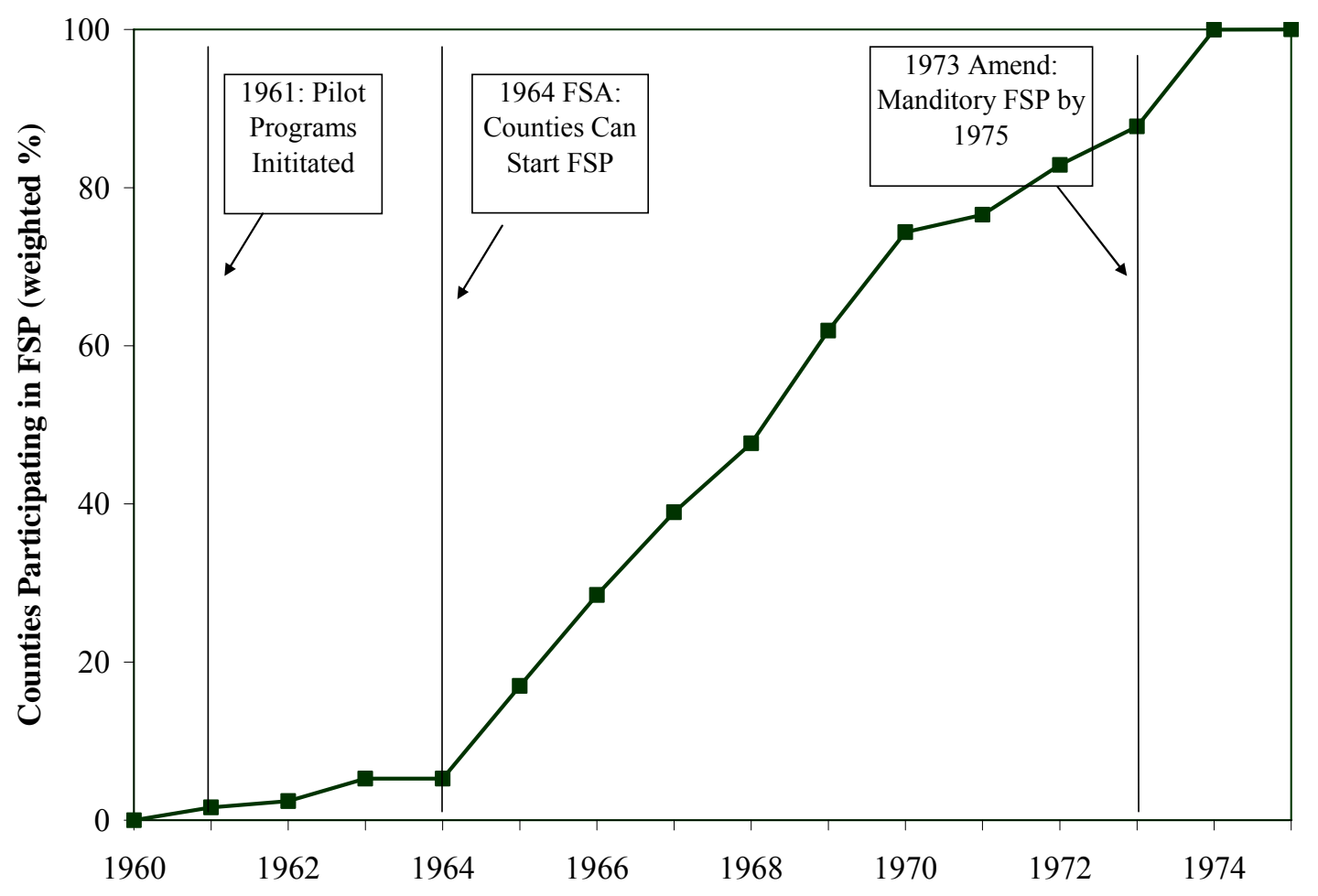

Source: Author's tabulations of county FSP start dates. Counties are weighted by their 1960 population. 
Figure 2: Food Assistance Program Participation, 1968-1976

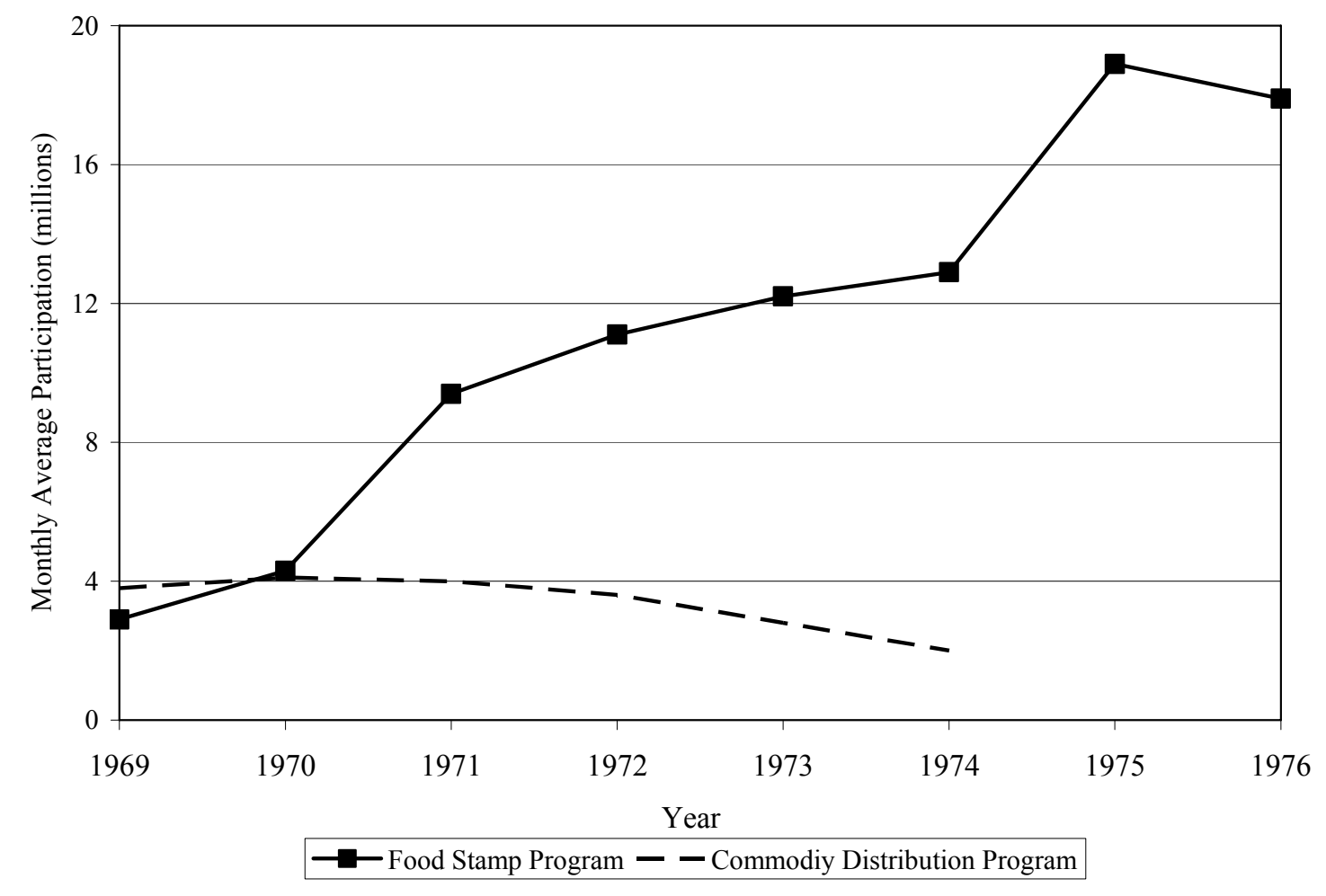

Source: Berry (1984), Table 3. 
Figure 3: Food Stamp Program Start Date, By County (1961-1975)

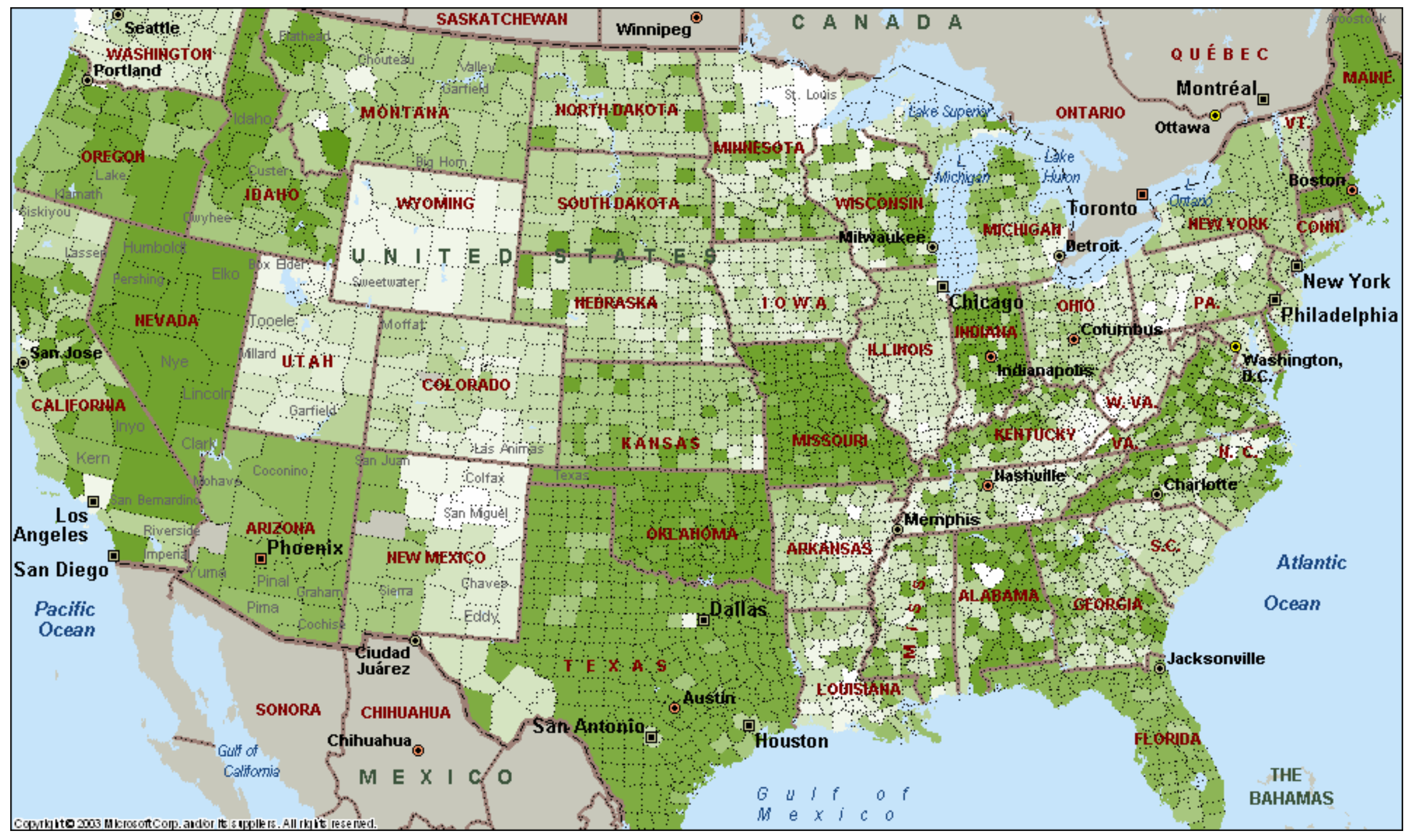

Note: Authors' tabulations of food stamp administrative data (U.S. Department of Agriculture, various years). 
Figure 4: Percent of Counties with Food Stamp Program 1961-1975, By State

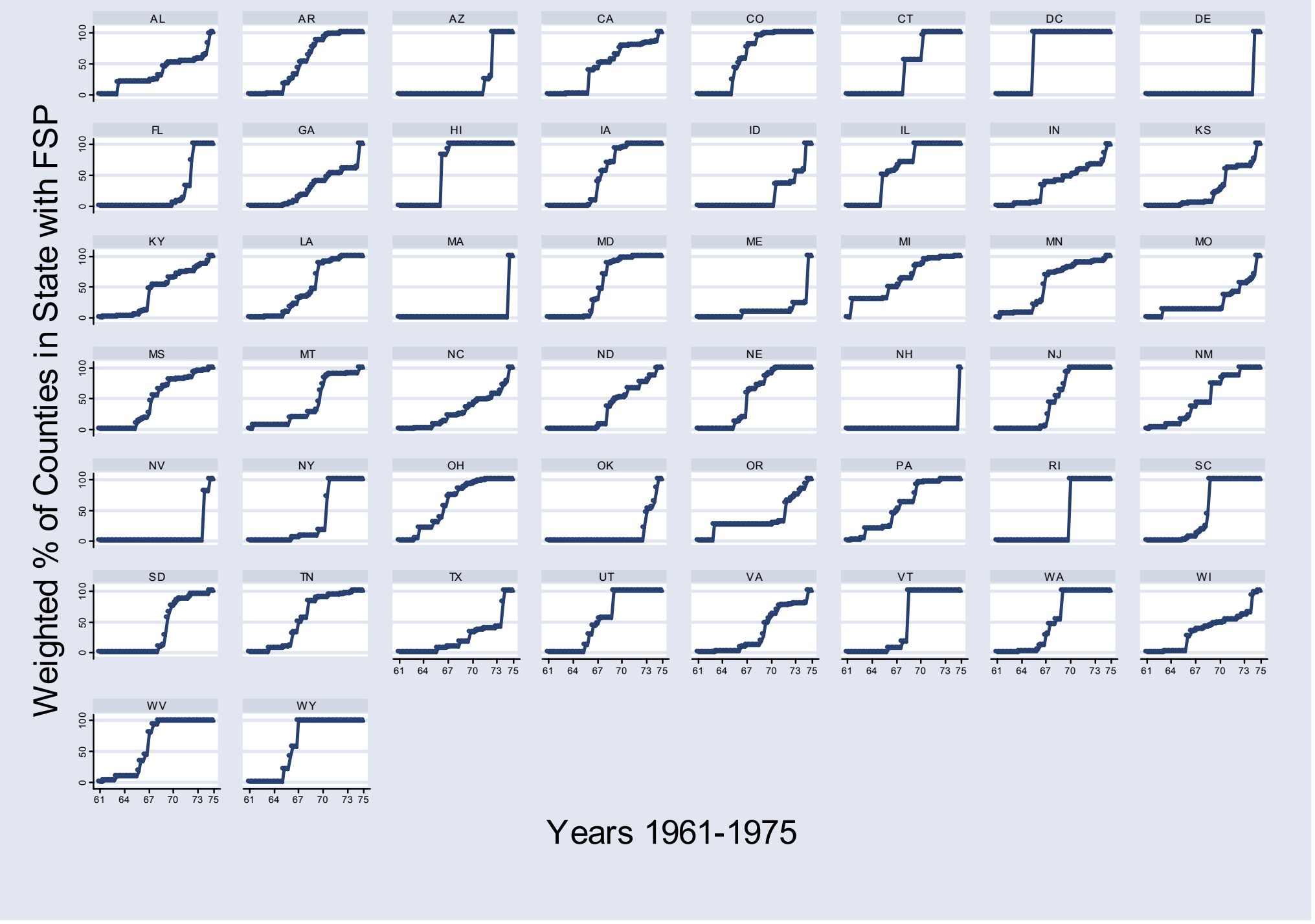

Source: Authors' tabulations of food stamp administrative data (U.S. Department of Agriculture, various years). Counties weighted by 1960 population. 
Figure 5: 1960 County Characteristics and County Food Stamp Start Date

(a) Percent Black

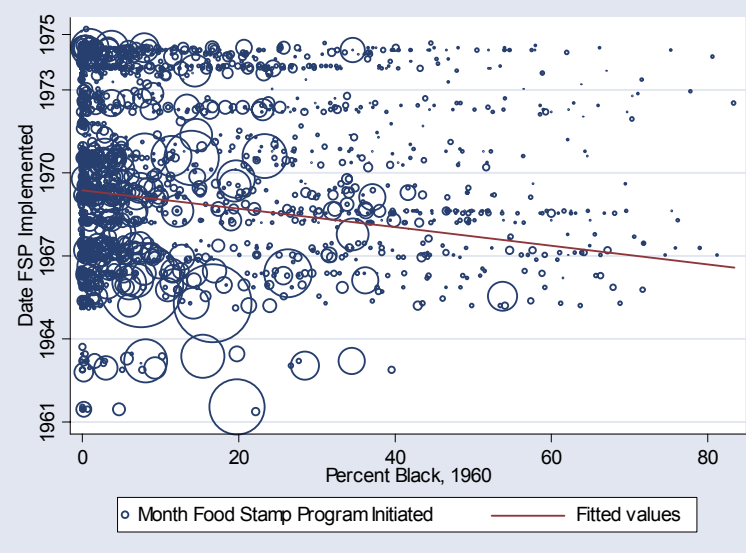

(b) Log of Population

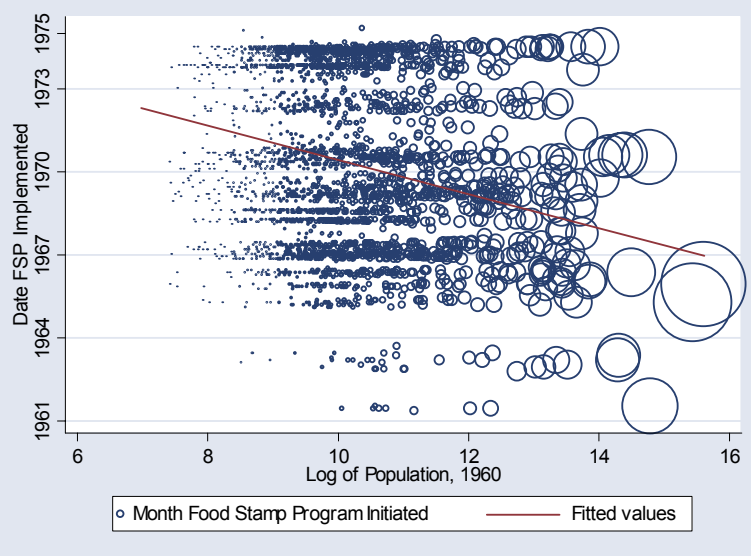

(c) Percent with Income $<\$ 3,000$

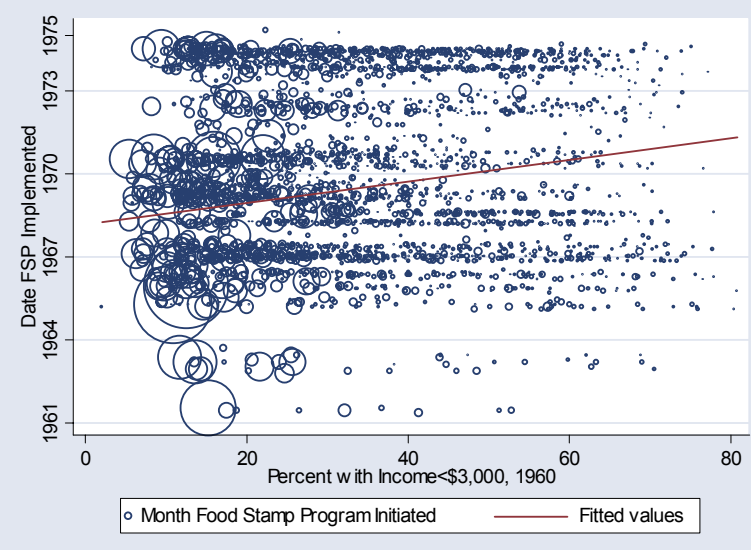

(d) Percent Urban

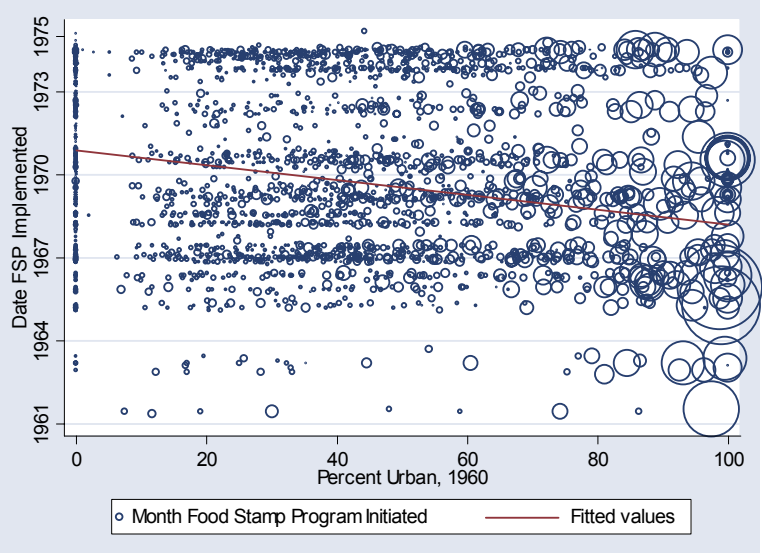

(e) Percent of Land in Farming

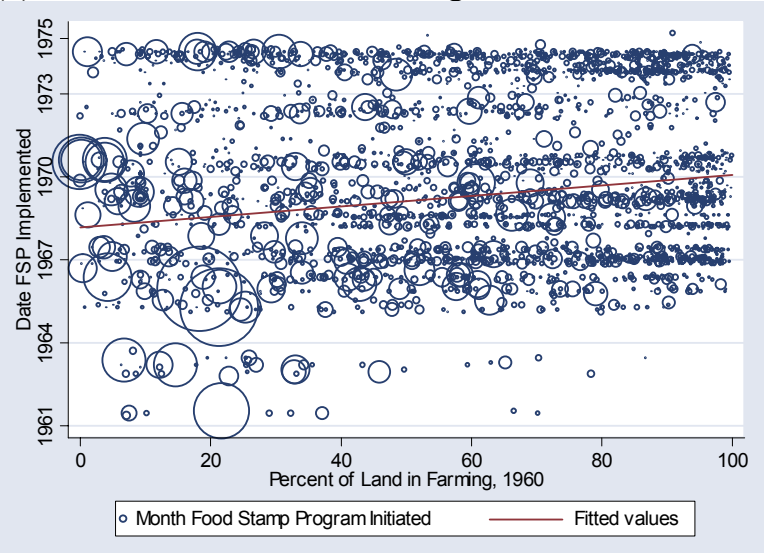

(f) Percent Age $>65$

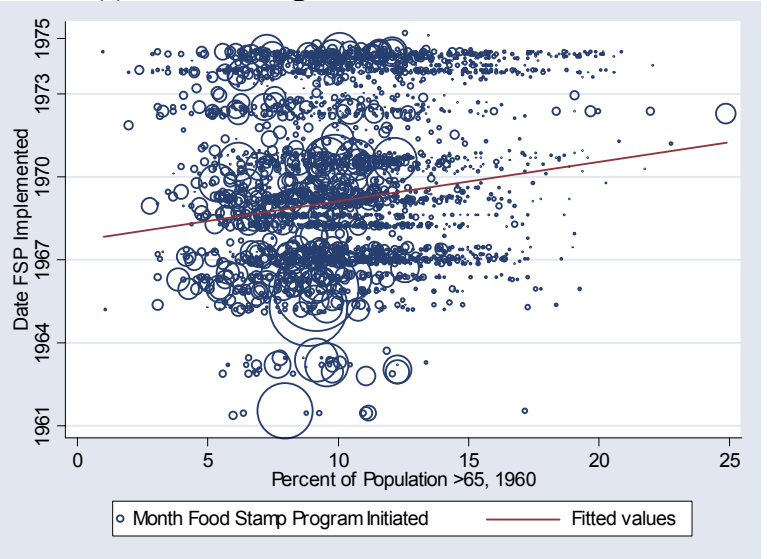

Note: Each graph provides a scatterplot of a 1960 county characteristic (x-axis) against the food stamp start date (yaxis) where the points are weighted by the 1960 county population. The graphs also contain the linear fit where the regression is weighted by 1960 county population. 1960 County characteristics are from the 1960 City and County Databook and the FSP implementation dates are from U.S. Department of Agriculture (various years). 
Figure 6: Food Stamps and Food/Non-Food Consumption: No Purchase Requirement

(a) Basic budget constraint with and without food stamps

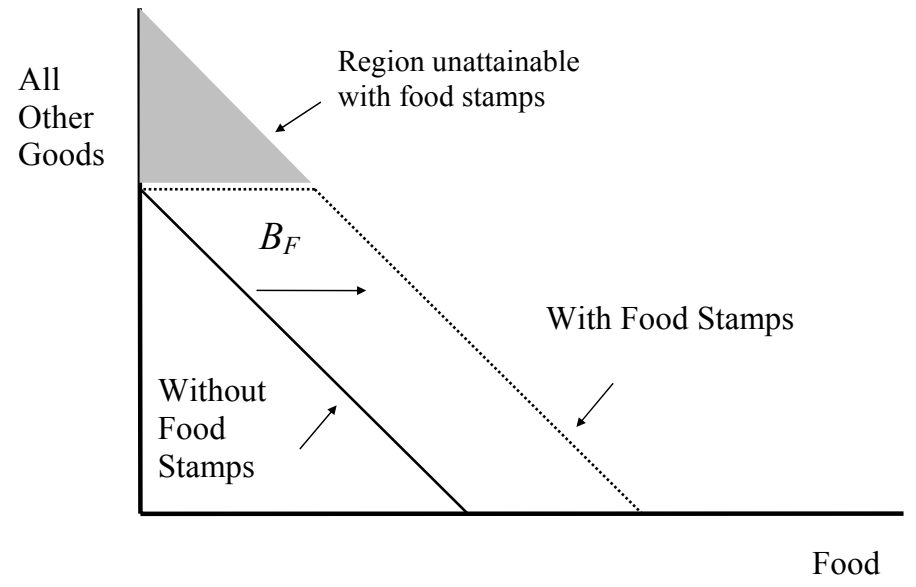

(b) FSP and consumption

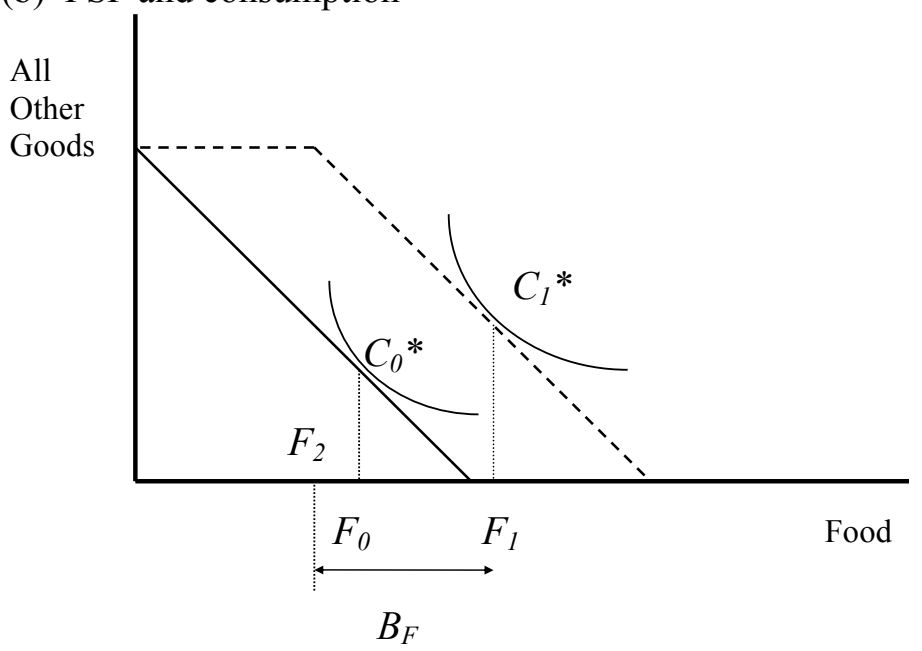

(c) FSP and consumption: constrained outcome

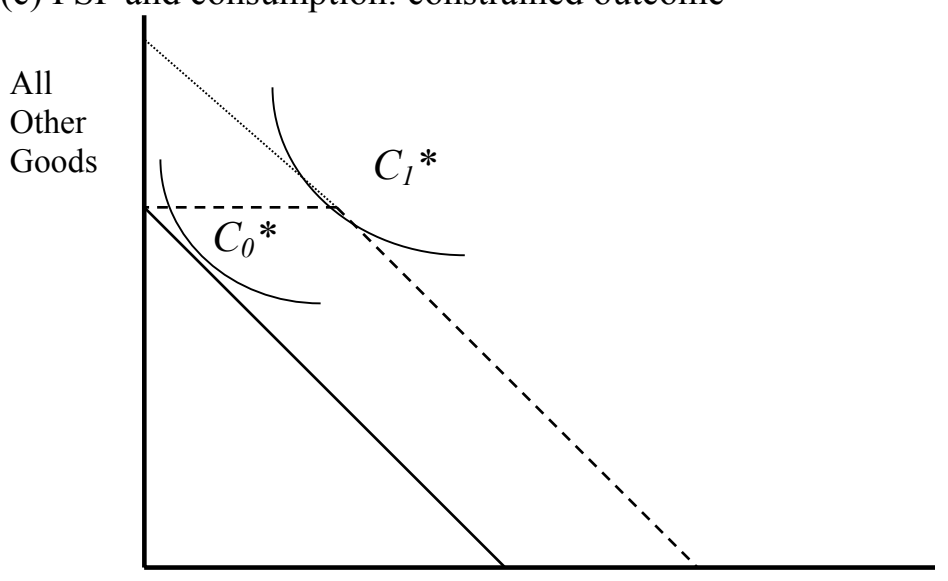

Food 
Figure 7: Food Stamps and Food/Nonfood Consumption: With Purchase Requirement

(a) Basic budget constraint with and without food stamps

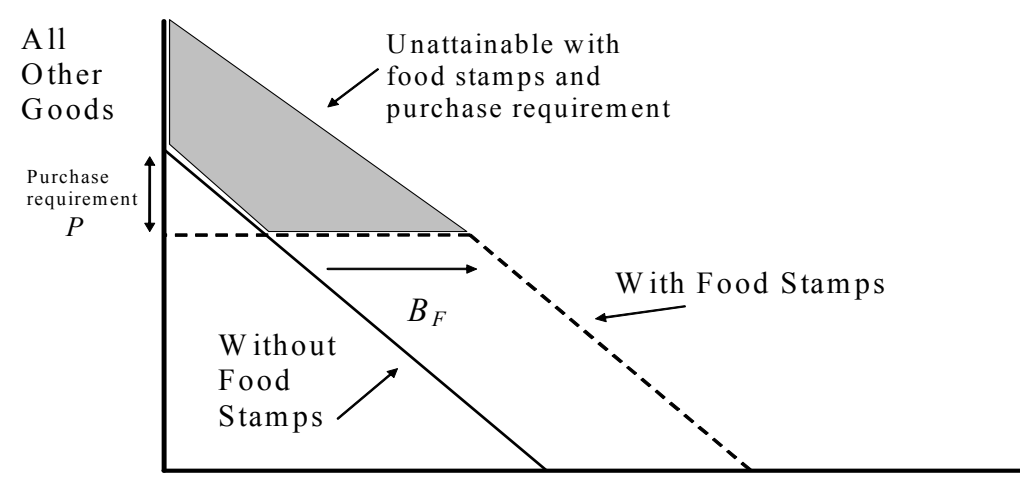

Food

\section{(b) FSP and consumption}

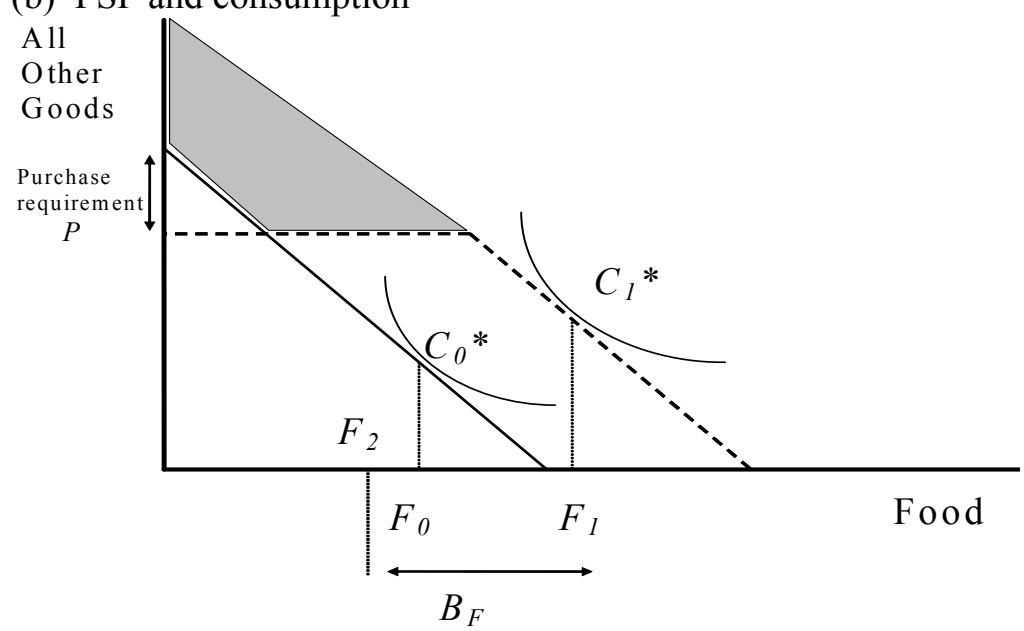

(c) Variable purchase option

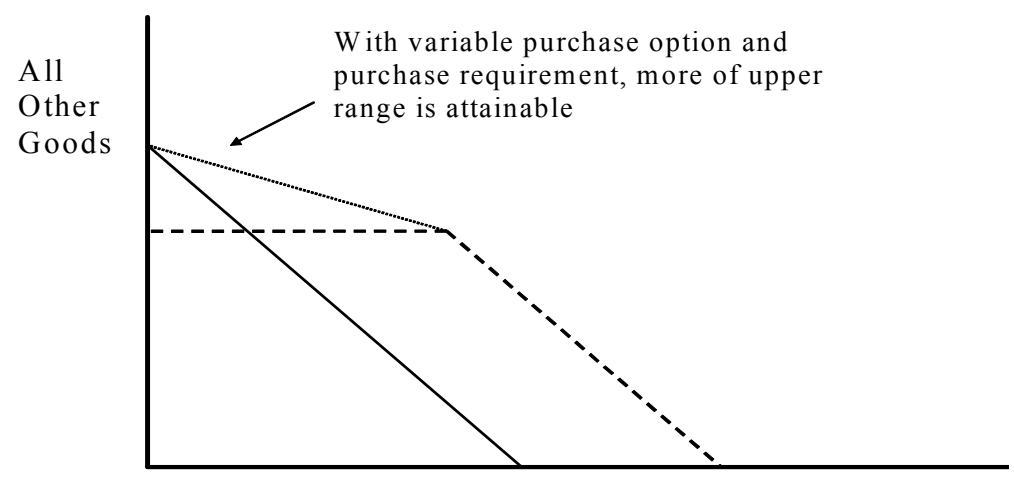

Food 
Table 1: Determinants of County Level Food Stamp Program Start Date Analysis Using the 1960 City and County Data Book

\begin{tabular}{|c|c|c|c|c|}
\hline & \multicolumn{2}{|c|}{ All Counties } & \multicolumn{2}{|c|}{ Limiting to post-pilot counties } \\
\hline & $(1)$ & (2) & (3) & (4) \\
\hline \multirow[t]{2}{*}{ Percent of land in farming } & -0.025 & 0.124 & 0.114 & 0.136 \\
\hline & $(0.830)$ & $(0.028)^{* * *}$ & $(0.027)^{* * *}$ & $(0.033)^{* * *}$ \\
\hline \multirow[t]{2}{*}{ Percent of pop with income $<\$ 3000$} & 0.005 & -0.544 & -0.347 & 0.085 \\
\hline & $(0.050)$ & $(0.092)^{* * *}$ & $(0.088)^{* * *}$ & $(0.147)$ \\
\hline \multirow[t]{2}{*}{ Percent of pop urban } & 0.214 & -0.068 & -0.040 & -0.001 \\
\hline & $(4.36)^{* *}$ & $(0.041)$ & $(0.039)$ & $(0.053)$ \\
\hline \multirow[t]{2}{*}{ Percent of pop black } & -0.326 & -0.208 & -0.212 & -0.474 \\
\hline & $(4.36)^{* *}$ & $(0.070)^{* * *}$ & $(0.067)^{* * *}$ & $(0.145)^{* * *}$ \\
\hline \multirow[t]{2}{*}{ Percent of pop age $<5$} & -3.566 & -2.329 & -2.954 & -3.557 \\
\hline & $(4.92)^{* *}$ & $(0.625)^{* * *}$ & $(0.593)^{* * *}$ & $(0.786)^{* * *}$ \\
\hline \multirow[t]{2}{*}{ Percent of pop age $>65$} & -1.030 & -0.982 & -1.133 & -3.048 \\
\hline & $(2.49)^{*}$ & $(0.390)^{* *}$ & $(0.371)^{* * *}$ & $(0.524)^{* * *}$ \\
\hline \multirow[t]{2}{*}{ log population } & -11.229 & -9.139 & -7.819 & -7.335 \\
\hline & $(13.44)^{* *}$ & $(0.752)^{* * *}$ & $(0.718)^{* * *}$ & $(0.932)^{* * *}$ \\
\hline \multicolumn{3}{|l|}{ South $* \%$ of land in farming } & & $\begin{array}{c}-0.125 \\
(0.058)^{* *}\end{array}$ \\
\hline \multirow[t]{2}{*}{ South $* \%$ pop with income $<\$ 3000$} & & & & -0.603 \\
\hline & & & & $(0.188)^{* * *}$ \\
\hline South * \% pop urban & & & & $\begin{array}{l}-0.110 \\
(0.080)\end{array}$ \\
\hline South * \% pop black & & & & 0.373 \\
\hline \multirow{2}{*}{ South $* \%$ pop age $<5$} & & & & \\
\hline & & & & $\begin{array}{c}0.787 \\
(1.222)\end{array}$ \\
\hline \multirow[t]{2}{*}{ South $* \%$ pop age $>65$} & & & & 3.467 \\
\hline & & & & $(0.754)^{* * *}$ \\
\hline South * log population & & & & $\begin{array}{c}0.645 \\
(1548)\end{array}$ \\
\hline State Fixed Effects & & $\mathrm{X}$ & $\mathrm{X}$ & $\mathrm{X}$ \\
\hline Number of Observations & 2,957 & 2,957 & 2,939 & 2,939 \\
\hline $\mathrm{R}$ squared & 0.14 & 0.56 & 0.55 & 0.56 \\
\hline
\end{tabular}

Notes: The data is at the county level and the dependent variable is equal to the calendar month (normed to 1 in January 1961) that the county began offering the Food Stamp Program. The control variables come from the City and County Databook for 1960. Alaska counties are dropped due to missing data on the food stamp program. Very small counties (with population less than 1,000) are dropped because of missing data on some control variables. A small number of counties are dropped because the variable percent of land in farming exceeds 100 percent. Estimates are weighted using the 1960 county population. 
Table 2

Food Stamp Participation Rates by Demographic Group

\begin{tabular}{|c|c|c|c|c|}
\hline & \multicolumn{4}{|c|}{ Education Group } \\
\hline & All & Less than HS & $\begin{array}{c}\text { High School } \\
\text { Grad }\end{array}$ & More than HS \\
\hline \multicolumn{5}{|l|}{ A. All Races } \\
\hline All family types & 0.08 & 0.14 & 0.06 & 0.02 \\
\hline Single with children & 0.32 & 0.46 & 0.23 & 0.15 \\
\hline Married with children & 0.07 & 0.14 & 0.06 & 0.01 \\
\hline Single, no children & 0.07 & 0.14 & 0.05 & 0.03 \\
\hline Married, no children & 0.02 & 0.04 & 0.01 & 0.01 \\
\hline Single, no children elderly & 0.07 & 0.10 & 0.03 & 0.01 \\
\hline Married, no children elderly & 0.03 & 0.05 & 0.00 & 0.00 \\
\hline \multicolumn{5}{|l|}{ B. White } \\
\hline All family types & 0.05 & 0.10 & 0.04 & 0.02 \\
\hline Single with children & 0.22 & 0.38 & 0.14 & 0.07 \\
\hline Married with children & 0.05 & 0.12 & 0.05 & 0.01 \\
\hline Single, no children & 0.05 & 0.11 & 0.04 & 0.03 \\
\hline Married, no children & 0.01 & 0.03 & 0.00 & 0.01 \\
\hline Single, no children elderly & 0.05 & 0.07 & 0.02 & 0.01 \\
\hline Married, no children elderly & 0.02 & 0.04 & 0.00 & 0.00 \\
\hline \multicolumn{5}{|l|}{ C. Nonwhite } \\
\hline$\overline{\text { All family types }}$ & 0.22 & 0.28 & 0.18 & 0.09 \\
\hline Single with children & 0.51 & 0.56 & 0.44 & 0.43 \\
\hline Married with children & 0.16 & 0.22 & 0.14 & 0.03 \\
\hline Single, no children & 0.13 & 0.20 & 0.09 & 0.04 \\
\hline Married, no children & 0.06 & 0.10 & 0.02 & 0.02 \\
\hline Single, no children elderly & 0.24 & 0.25 & 0.11 & 0.00 \\
\hline Married, no children elderly & 0.10 & 0.13 & 0.00 & 0.00 \\
\hline
\end{tabular}

Notes: Weighted means of food stamp participation rates using families in the 1976-1978 Panel Study of Income Dynamics. These years were chosen because by 1976 all counties had implemented food stamp programs yet it was before the elimination of the purchase requirement in 1979. 
Table 3

Impact of Food Stamp Introduction on Family Food Expenditures

All Nonelderly Singles and Families

(1)

(2)

(3)

(4)

$(5)$

A. $\log ($ Real Expenditures on Food at Home)

County FSP Implemented X

Group Participation Rate

Number of Observations

R Squared

B. Any Meals Out (0/1)

County FSP Implemented X

Group Participation Rate

Number of Observations

R Squared

C. Log (Real Total Food Expenditures)

County FSP Implemented X

Group Participation Rate

Number of Observations

$\underline{\mathrm{R} \text { Squared }}$

Demographics

1960 Cty Vars * Linear Time

Year and County Fixed Effects

Group Fixed Effects

Group * linear time

Per Capita Cty Transfers

Log(Real Family Income)

State $x$ Linear Time

State $\mathrm{x}$ Year Fixed Effects

$\begin{array}{ccccc}0.061 & -0.034 & -0.034 & -0.042 & -0.050 \\ (0.089) & (0.094) & (0.093) & (0.085) & (0.090) \\ 39,243 & 39,243 & 39,243 & 39,243 & 39,243 \\ 0.56 & 0.56 & 0.56 & 0.60 & 0.61\end{array}$

$\begin{array}{lllll}-0.109 & -0.040 & -0.040 & -0.045 & -0.046\end{array}$

$\begin{array}{lllll}(0.081) & (0.081) & (0.082) & (0.082) & (0.085)\end{array}$

$39,623 \quad 39,623 \quad 39,623 \quad 39,623 \quad 39,623$

$\begin{array}{lllll}0.27 & 0.27 & 0.27 & 0.29 & 0.30\end{array}$

$\begin{array}{lllll}0.212 & 0.184 & 0.184 & 0.174 & 0.179\end{array}$

$\begin{array}{lllll}(0.080)^{* * *} & (0.082)^{* *} & (0.082)^{* *} & (0.073)^{* *} & (0.075)^{* *}\end{array}$

$39,623 \quad 39,623 \quad 39,623 \quad 39,623 \quad 39,623$

$\begin{array}{lllll}0.53 & 0.54 & 0.54 & 0.60 & 0.60\end{array}$

$\begin{array}{lllll}\mathrm{X} & \mathrm{X} & \mathrm{X} & \mathrm{X} & \mathrm{X} \\ \mathrm{X} & \mathrm{X} & \mathrm{X} & \mathrm{X} & \mathrm{X} \\ \mathrm{X} & \mathrm{X} & \mathrm{X} & \mathrm{X} & \mathrm{X} \\ \mathrm{X} & \mathrm{X} & \mathrm{X} & \mathrm{X} & \mathrm{X} \\ \mathrm{X} & \mathrm{X} & \mathrm{X} & \mathrm{X} & \mathrm{X} \\ & & \mathrm{X} & \mathrm{X} & \mathrm{X} \\ & & & \mathrm{X} & \mathrm{X} \\ & \mathrm{X} & \mathrm{X} & \mathrm{X} & \end{array}$

Notes: Each parameter is from a separate regression of the outcome variable on the Food Stamp implementation dummy multiplied by a group food stamp participation rate. The food stamp implementation dummy equals one if the county-year observation had a food stamp program in place by January of that year. The group food stamp participation rate is calculated for each education-race-marital status-presence of children cell using the 1976-1978 PSID. The estimation sample includes all PSID families with nonelderly heads in interview years 1969-1972 and 19741978. There is no food data in 1973 and 1978 is chosen due to the purchase requirement being eliminated is as of 1979 . Observations from Alaska are dropped because of missing data on food stamp program start date and observations with unusual expenditure values are dropped (annual food expenditures less than $\$ 100$, annual family income less than $\$ 500$, or income share on food greater than 0.85 ). All outcome variables correspond to annual measures taken as of the interview (in spring of the interview year). Demographic controls include dummies for education, number of children, number of adults, race, urban location and state unemployment rate. 1960 county variables include log of population, percent of land in farming, percent of population black, urban, age $<5$, age $>65$ and with income less than $\$ 3,000$ each interacted with a linear time trend. Per capita county transfer income comes from the BEA REIS and includes measures for public assistance (AFDC, General Assistance), medical care (Medicare, Medicaid, military), and retirement and disability benefits. Estimates are weighted using the PSID weight and clustered on county. Standard errors are in parentheses and ***,**, and * indicate that the estimates are significant at the $1 \%, 5 \%$ and $10 \%$ levels. 
Table 4

Impact of Food Stamp Introduction on Family Food Expenditures

Female Headed Households with Children

(1)

(2)

(3)

(4)

$(5)$

\begin{tabular}{|c|c|c|c|c|c|}
\hline \multicolumn{6}{|l|}{ A. Any Food Stamps $(0 / 1)$} \\
\hline \multirow[t]{3}{*}{ County FSP Implemented } & 0.158 & 0.186 & 0.194 & 0.200 & 0.190 \\
\hline & $(0.040)^{* * *}$ & $(0.040)^{* * *}$ & $(0.040)^{* * *}$ & $(0.040)^{* * *}$ & $(0.040) * * *$ \\
\hline & 0.436 & 0.514 & 0.536 & 0.552 & 0.525 \\
\hline Number of Observations & 6002 & 6002 & 6002 & 6002 & 6002 \\
\hline R Squared & 0.39 & 0.40 & 0.40 & 0.46 & 0.49 \\
\hline \multicolumn{6}{|c|}{ B. $\log ($ Real Expenditures on Food at Home $)$} \\
\hline \multirow[t]{3}{*}{ County FSP Implemented } & -0.008 & 0.034 & 0.042 & 0.031 & 0.008 \\
\hline & $(0.053)$ & $(0.055)$ & $(0.055)$ & $(0.054)$ & $(0.070)$ \\
\hline & -0.022 & 0.094 & 0.116 & 0.086 & 0.022 \\
\hline Number of Observations & 5788 & 5788 & 5788 & 5788 & 5788 \\
\hline R Squared & 0.43 & 0.45 & 0.45 & 0.51 & 0.55 \\
\hline \multicolumn{6}{|l|}{ C. Any Meals Out (0/1) } \\
\hline \multirow[t]{3}{*}{ County FSP Implemented } & -0.080 & -0.051 & -0.055 & -0.060 & -0.060 \\
\hline & $(0.048)^{*}$ & $(0.048)$ & $(0.048)$ & $(0.048)$ & $(0.048)$ \\
\hline & -0.221 & -0.141 & -0.152 & -0.166 & -0.166 \\
\hline Number of Observations & 6002 & 6002 & 6002 & 6002 & 6002 \\
\hline R Squared & 0.36 & 0.37 & 0.38 & 0.40 & 0.40 \\
\hline \multicolumn{6}{|c|}{$\underline{\text { D. Log (Real Total Food Expenditures) }}$} \\
\hline \multirow[t]{3}{*}{ County FSP Implemented } & 0.039 & 0.095 & 0.102 & 0.095 & 0.095 \\
\hline & $(0.039)$ & $(0.043)^{* *}$ & $(0.042)^{* *}$ & $(0.041)^{* *}$ & $(0.049)^{*}$ \\
\hline & 0.108 & 0.262 & 0.282 & 0.262 & 0.262 \\
\hline Number of Observations & 6002 & 6002 & 6002 & 6002 & 6002 \\
\hline$\underline{\text { R Squared }}$ & 0.48 & 0.49 & 0.49 & 0.55 & 0.58 \\
\hline Demographics & $\mathrm{X}$ & $\mathrm{X}$ & $X$ & $\mathrm{X}$ & $\mathrm{X}$ \\
\hline 1960 Cty Vars * Linear Time & $\mathrm{X}$ & $\mathrm{X}$ & $\mathrm{X}$ & $\mathrm{X}$ & $\mathrm{X}$ \\
\hline Year and County Fixed Effects & $X$ & $\mathrm{X}$ & $\mathrm{X}$ & $X$ & $\mathrm{X}$ \\
\hline Per Capita Cty Transfers & & & $\mathrm{X}$ & $\mathrm{X}$ & $\mathrm{X}$ \\
\hline Log(Real Family Income) & & & & $\mathrm{X}$ & $\mathrm{X}$ \\
\hline State $\mathrm{x}$ Linear Time & & $\mathrm{X}$ & $X$ & $X$ & \\
\hline State $\mathrm{x}$ Year Fixed Effects & & & & & $\mathrm{X}$ \\
\hline
\end{tabular}

Notes: Each parameter is from a separate regression of the outcome variable on a dummy variable equal to 1 if the county-year observation had a food stamp program in place by January of that year. The sample includes PSID families with children headed by an unmarried woman using interview years 1969-1972 and 1974-1978. There is no food data in 1973 and 1978 is chosen due to the purchase requirement being eliminated as of 1979. Observations from Alaska are dropped because of missing data on food stamp program start date and observations with unusual expenditure values are dropped (annual food expenditures less than $\$ 100$, annual family income less than $\$ 500$, or income share on food greater than 0.85). All outcome variables correspond to annual measures taken as of the interview (in spring of the interview year). Demographic controls include dummies for education, number of children, and number of adults, race, urban location and state unemployment rate. 1960 county variables include log of population, percent of land in farming, percent of population black, urban, age $<5$, age $>65$ and with income less than $\$ 3,000$ each interacted with a linear time trend. Per capita county transfer income comes from the BEA REIS and includes measures for public assistance (AFDC, General Assistance), medical care (Medicare, Medicaid, military), and retirement and disability benefits. Estimates are weighted using the PSID weight and clustered on county. Standard errors are in parentheses and ***,**, and * indicate that the estimates are significant at the $1 \%, 5 \%$ and $10 \%$ levels. The numbers in italics inflate the parameter estimate by the sample food stamp participation rate in 1978. 
Table 5

Impact of Food Stamp Introduction on Family Food Expenditures

Nonwhite Female Headed Households with Children

(1)

(2)

(3)

(4)

(5)

A. Any Food Stamps (0/1)
County FSP Implemented

0.300

0.373

0.379

0.363

0.188

$\begin{array}{cc}(0.053)^{* * *} & (0.067)^{* * *} \\ 0.550 & 0.684\end{array}$

$(0.070)^{* * *}$

$(0.074)^{* * *}$

$(0.064)^{* * *}$

Number of Observations

4501

4501

0.695

0.666

0.345

R Squared

0.33

0.35

4501

4501

4501

B. Log(Real Expenditures on Food at Home)

County FSP Implemented

$-0.031$

$-0.062$

0.35

0.40

0.47

\begin{tabular}{lccccc} 
County FSP Implemented & -0.031 & -0.062 & -0.090 & -0.067 & -0.094 \\
& $(0.077)$ & $(0.056)$ & $(0.058)$ & $(0.054)$ & $(0.064)$ \\
& -0.057 & -0.114 & -0.165 & -0.123 & -0.172 \\
Number of Observations & 4311 & 4311 & 4311 & 4311 & 4311 \\
R Squared & 0.39 & 0.41 & 0.41 & 0.48 & 0.54 \\
C. Any Meals Out (0/1) & & & & & \\
County FSP Implemented & -0.036 & -0.066 & -0.067 & -0.056 & -0.013 \\
& $(0.060)$ & $(0.058)$ & $(0.059)$ & $(0.060)$ & $(0.070)$ \\
& -0.066 & -0.121 & -0.123 & -0.103 & -0.024 \\
Number of Observations & 4501 & 4501 & 4501 & 4501 & 4501 \\
R Squared & 0.26 & 0.28 & 0.28 & 0.31 & 0.38 \\
D. Log (Real Total Food Expenditures) & & & & & \\
County FSP Implemented & 0.071 & 0.039 & 0.036 & 0.055 & 0.031 \\
& $(0.060)$ & $(0.047)$ & $(0.048)$ & $(0.045)$ & $(0.053)$ \\
& 0.130 & 0.072 & 0.066 & 0.101 & 0.057 \\
Number of Observations & 4501 & 4501 & 4501 & 4501 & 4501 \\
R Squared & 0.43 & 0.46 & 0.46 & 0.51 & 0.55 \\
\hline & & & & & \\
Demographics & $\mathrm{X}$ & $\mathrm{X}$ & $\mathrm{X}$ & $\mathrm{X}$ & $\mathrm{X}$ \\
1960 Cty Vars * Linear Time & $\mathrm{X}$ & $\mathrm{X}$ & $\mathrm{X}$ & $\mathrm{X}$ & $\mathrm{X}$ \\
Year and County Fixed Effects & $\mathrm{X}$ & $\mathrm{X}$ & $\mathrm{X}$ & $\mathrm{X}$ & $\mathrm{X}$ \\
Per Capita Cty Transfers & & & $\mathrm{X}$ & $\mathrm{X}$ & $\mathrm{X}$ \\
Log(Real Family Income) & & $\mathrm{X}$ & $\mathrm{X}$ & $\mathrm{X}$ & $\mathrm{X}$ \\
State x Linear Time & & & & & $\mathrm{X}$ \\
State x Year Fixed Effects & & & & & \\
\hline \hline
\end{tabular}

Notes: Each parameter is from a separate regression of the outcome variable on a dummy variable equal to 1 if the county-year observation had a food stamp program in place by January of that year. The sample includes PSID families with children headed by an unmarried woman using interview years 1969-1972 and 1974-1978. There is no food data in 1973 and 1978 is chosen due to the purchase requirement being eliminated is as of 1979. Observations from Alaska are dropped because of missing data on food stamp program start date and observations with unusual expenditure values are dropped (annual food expenditures less than $\$ 100$, annual family income less than $\$ 500$, or income share on food greater than 0.85). All outcome variables correspond to annual measures taken as of the interview (in spring of the interview year). Demographic controls include dummies for education, number of children, number of adults, race, urban location and state unemployment rate. 1960 county variables include log of population, percent of land in farming, percent of population black, urban, age $<5$, age $>65$ and with income less than $\$ 3,000$ each interacted with a linear time trend.. Per capita county transfer income comes from the BEA REIS and includes measures for public assistance (AFDC, General Assistance), medical care (Medicare, Medicaid, military), and retirement and disability benefits. Estimates are weighted using the PSID weight and clustered on county. Standard errors are in parentheses and $* * *, * *$, and * indicate that the estimates are significant at the $1 \%, 5 \%$ and $10 \%$ levels. The numbers in italics inflate the parameter estimate by the sample food stamp participation rate in 1978 . 
Table 6

Estimated Marginal Propensities to Consume Food Out of Food Stamps and Income

\begin{tabular}{|c|c|c|c|c|c|}
\hline & \multirow[b]{2}{*}{$\mathrm{N}$} & \multicolumn{2}{|c|}{ Regression Estimates } & \multicolumn{2}{|c|}{$\begin{array}{l}\text { Estimated } \mathrm{MPC}_{\mathrm{f}} \text { for } \\
\text { treated }\end{array}$} \\
\hline & & $\begin{array}{l}\text { Coef (SE) } \\
\text { FS Elig }\end{array}$ & $\begin{array}{c}\text { Coef (SE) } \\
\log (\text { income })\end{array}$ & $\begin{array}{c}\mathrm{MPC}_{\mathrm{f}} \text { Food } \\
\text { Stamps }\end{array}$ & $\begin{array}{l}\mathrm{MPC}_{\mathrm{f}} \\
\text { Income }\end{array}$ \\
\hline (1) All nonelderly singles and families & 39,623 & $\begin{array}{c}0.174 \\
(0.073)^{* *}\end{array}$ & $\begin{array}{c}0.295 \\
(0.007)^{* * *}\end{array}$ & 0.163 & 0.086 \\
\hline (2) Nonelderly $<=\$ 50,000$ & 23,660 & $\begin{array}{c}0.227 \\
(0.072)^{* * *}\end{array}$ & $\begin{array}{c}0.270 \\
(0.012)^{* * *}\end{array}$ & 0.209 & 0.086 \\
\hline (3) Nonelderly $<=\$ 35,000$ & 16,079 & $\begin{array}{c}0.228 \\
(0.083)^{* * *}\end{array}$ & $\begin{array}{c}0.262 \\
(0.015)^{* * *}\end{array}$ & 0.201 & 0.091 \\
\hline (4) Nonelderly, $<=\$ 25,000$ & 13,048 & $\begin{array}{c}0.282 \\
(0.114)^{* *}\end{array}$ & $\begin{array}{c}0.285 \\
(0.024)^{* * *}\end{array}$ & 0.238 & 0.111 \\
\hline (5) Nonelderly, head $<=12$ yrs of educ & 30,905 & $\begin{array}{c}0.228 \\
(0.069)^{* * *}\end{array}$ & $\begin{array}{c}0.278 \\
(0.008)^{* * *}\end{array}$ & 0.219 & 0.084 \\
\hline (6) Nonelderly, nonwhite & 15,990 & $\begin{array}{c}0.258 \\
(0.079)^{* * *}\end{array}$ & $\begin{array}{c}0.270 \\
(0.014)^{* * *}\end{array}$ & 0.317 & 0.086 \\
\hline \multirow[t]{2}{*}{ (7) All female heads } & 6,002 & $\begin{array}{c}0.095 \\
(0.041)^{* *}\end{array}$ & $\begin{array}{l}0.289 \\
(0.019)^{* * *}\end{array}$ & 0.297 & 0.098 \\
\hline & & 0.262 & & & \\
\hline \multirow[t]{2}{*}{ (8) Nonwhite female heads } & 4,501 & $\begin{array}{c}0.055 \\
(0.045)\end{array}$ & $\begin{array}{c}0.286 \\
(0.026)^{* * *}\end{array}$ & 0.165 & 0.101 \\
\hline & & 0.101 & & & \\
\hline
\end{tabular}

Notes: Each row reports results from a separate regression of the log of total food spending on the FSP treatment, the log of real family income, demographics, county variables, and fixed effects. The results in rows (1)-(6) are estimated on the sample of nonelderly singles and families where the specification is identical to column (4) in Table 3. The treatment effect (coefficient on county FSP implementation) is scaled up to reflect the impact per food stamp participant family. This is because in the estimating equation the treatment dummy is multiplied by the food stamp participation rate, assigned by education-marital status-race-presence of children cells. The results in rows (7)-(8) correspond to the specification in column (4) in Tables 4-5. The numbers in italics inflate the treatment effect by the sample food stamp participation rate in 1978. See the notes to tables 3-5 for more details. Standard errors are in parentheses and $* * *, * *$, and * indicate that the estimates are significant at the $1 \%, 5 \%$ and $10 \%$ levels. Estimates are weighted using the PSID weight and clustered on county. All samples trim the data to drop observations with unusual expenditure values (annual food expenditures less than $\$ 100$, annual family income less than $\$ 500$, or income share on food greater than 0.85 ). The marginal propensities to consume food are evaluated at mean values for food expenditures and family income among food stamp recipient families. 
Table 7

Impact of Food Stamp Introduction on Family Food Expenditures

Estimates on Placebo groups

\begin{tabular}{cccc} 
Any Food & Log Real Exp on & Any Meals Out & Log of Real \\
Stamps $(0 / 1)$ & Food at Home & $(0 / 1)$ & Total Food Exp \\
\hline
\end{tabular}

A. High Income Families $(>\$ 50,000$ in $2005 \$)$

County FSP Implemented $\quad 0.005$

$(0.003)$

0.002

$-0.031$

$-0.009$

County FSP Implemented

16,797

(0.015)

$(0.018)^{*}$

$(0.014)$

Number of Observations

0.10

16,787

16,797

16,797

R Squared

0.58

0.21

0.51

B. High Income Married Families with Children $(>=\$ 50,000$ in $2005 \$)$

\begin{tabular}{lcccc}
\hline County FSP Implemented & 0.004 & -0.003 & -0.010 & -0.023 \\
& $(0.004)$ & $(0.018)$ & $(0.020)$ & $(0.019)$ \\
Number of Observations & 9,814 & 9,808 & 9,814 & 9,814 \\
R Squared & 0.13 & 0.51 & 0.25 & 0.51
\end{tabular}

C. White High Educated Married Families with Children

\begin{tabular}{lcccc}
\hline County FSP Implemented & 0.003 & -0.035 & -0.016 & -0.066 \\
& $(0.003)$ & $(0.033)$ & $(0.035)$ & $(0.032)^{* *}$ \\
Number of Observations & 1,947 & 1,947 & 1,947 & 1,947 \\
R Squared & 0.29 & 0.67 & 0.30 & 0.67 \\
\hline \hline
\end{tabular}

Notes: Each parameter is from a separate regression of the outcome variable on a dummy variable equal to 1 if the county-year observation had a food stamp program in place by January of that year. The models correspond to specification (4) in Table 4. See the notes to that table for more details. Standard errors are in parentheses and ***,**, and * indicate that the estimates are significant at the 1\%,5\% and $10 \%$ levels. Estimates are weighted using the PSID weight and clustered on county. Each panel corresponds to estimates from a different sample. The first panel includes families where family income exceeds $\$ 50,000$. The second panel takes the high income sample and restricts it further to include married families with children. The third panel includes white married families with children where the head has 16 or more years of education. All samples trim the data to drop observations with unusual expenditure values (annual food expenditures less than $\$ 100$, annual family income less than $\$ 500$, or income share on food greater than 0.85 ). 
Table 8

Impact of Food Stamp Introduction on Family Food Expenditures

Specification Tests: All nonelderly singles and families

\begin{tabular}{lccc}
\hline \hline & $\begin{array}{c}\text { Log Real Exp on } \\
\text { Food at Home }\end{array}$ & $\begin{array}{c}\text { Any Meals Out } \\
(0 / 1)\end{array}$ & $\begin{array}{c}\text { Log of Real } \\
\text { Total Food Exp }\end{array}$ \\
\hline A. Drop allocated observations & & & \\
County FSP Implemented X & -0.036 & -0.061 & 0.164 \\
$\quad$ Group participation rate & $(0.085)$ & $(0.081)$ & $(0.073)^{* *}$ \\
Number of Observations & 37,172 & 39,211 & 37,088 \\
R Squared & 0.61 & 0.30 & 0.60 \\
B. Add in trimmed observations & & & \\
County FSP Implemented X & -0.037 & -0.048 & 0.189 \\
$\quad$ Group participation rate & $(0.087)$ & $(0.081)$ & $(0.077)^{* *}$ \\
Number of Observations & 40,005 & 41,047 & 40,785 \\
R Squared & 0.58 & 0.29 & 0.57 \\
C. Add lead of policy variable & & & \\
County FSP Implemented X & -0.056 & -0.074 & 0.162 \\
$\quad$ Group participation rate & $(0.083)$ & $(0.096)$ & $(0.072)^{* *}$ \\
Lead of County FSP X & 0.035 & 0.072 & 0.028 \\
$\quad$ Group participation rate & $(0.104)$ & $(0.116)$ & $(0.107)$ \\
Number of Observations & 39,243 & 39,623 & 39,623 \\
R Squared & 0.60 & 0.29 & 0.60 \\
\hline \hline
\end{tabular}

Notes: Each parameter is from a separate regression of the outcome variable on a dummy variable equal to 1 if the county-year observation had a food stamp program in place by January of that year interacted with a group specific food stamp participation rate. The models correspond to specification (4) in Table 5 and are based on the sample of nonelderly singles and families. See the notes to that table for more details. Standard errors are in parentheses and $* * *, * *$, and $*$ indicate that the estimates are significant at the $1 \%, 5 \%$ and $10 \%$ levels. Estimates are weighted using the PSID weight and clustered on county. Each panel corresponds to estimates from a different sample or specification. Panel A drops observations where any food expenditure variables have been allocated (imputed). Panel B adds back in the trimmed observations (those with annual food expenditures less than $\$ 100$, annual family income less than $\$ 500$, or income share on food greater than 0.85 ). Panel $\mathrm{C}$ includes a one year lead of the policy variable. 
Table 9

Impact of Food Stamp Introduction on Total Food Expenditures

Sensitivity to Alternative Functional Form

\begin{tabular}{|c|c|c|c|c|}
\hline Specification & $\log -\log$ & semi-log & linear & quadratic \\
\hline $\begin{array}{l}\text { Dependent Variable } \\
\text { Income }\end{array}$ & $\begin{array}{c}\log (\text { total food }) \\
\log (\text { income })\end{array}$ & $\begin{array}{c}\text { total food exp } \\
\log (\text { income })\end{array}$ & $\begin{array}{l}\text { total food exp } \\
\text { income }\end{array}$ & $\begin{array}{l}\text { total food exp } \\
\text { quad income }\end{array}$ \\
\hline \multicolumn{5}{|c|}{$\underline{\text { All Nonelderly singles and families }}$} \\
\hline $\begin{array}{l}\text { County FSP Implemented X } \\
\text { Group participation rate }\end{array}$ & $\begin{array}{c}0.174 \\
(0.073)^{* *}\end{array}$ & $\begin{array}{c}975 \\
(613)\end{array}$ & $\begin{array}{l}1138 \\
(611)^{*}\end{array}$ & $\begin{array}{l}1110 \\
(603)^{*}\end{array}$ \\
\hline $\log ($ income $)$ & $\begin{array}{l}0.295 \\
(0.007) * * *\end{array}$ & $\begin{array}{c}2,150 \\
(85)^{* * *}\end{array}$ & & \\
\hline income & & & $\begin{array}{l}0.038 \\
(0.002)^{* * *}\end{array}$ & $\begin{array}{l}0.048 \\
(0.003)^{* * *}\end{array}$ \\
\hline income squared $(/ \$ 10,000)$ & & & & $\begin{array}{l}0.000 \\
(0.000)^{* * *}\end{array}$ \\
\hline Number of Observations & 39,623 & 39,623 & 39,623 & 39,623 \\
\hline $\mathrm{R}$ squared & 0.60 & 0.57 & 0.59 & 0.59 \\
\hline Estimated MPC food stamps & 0.163 & 0.127 & 0.148 & 0.145 \\
\hline Estimated MPC income & 0.086 & 0.087 & 0.038 & 0.048 \\
\hline
\end{tabular}

Nonelderly singles and families with family income $<\$ 50,000(2005 \$)$

\begin{tabular}{|c|c|c|c|c|}
\hline $\begin{array}{c}\text { County FSP Implemented X } \\
\text { Group participation rate }\end{array}$ & $\begin{array}{c}0.227 \\
(0.072)^{* * *}\end{array}$ & $\begin{array}{c}1620 \\
(523)^{* * *}\end{array}$ & $\begin{array}{c}1670 \\
(523)^{* * *}\end{array}$ & $\begin{array}{c}1656 \\
(522)^{* * *}\end{array}$ \\
\hline $\log ($ income $)$ & $\begin{array}{l}0.270 \\
(0.012)^{* * *}\end{array}$ & $\begin{array}{c}1,163 \\
(54.461)^{* * *}\end{array}$ & & \\
\hline income & & & $\begin{array}{l}0.051 \\
(0.003)^{* * *}\end{array}$ & $\begin{array}{l}0.070 \\
(0.009)^{* * *}\end{array}$ \\
\hline income squared $(/ \$ 10,000)$ & & & & $\begin{array}{c}-0.003 \\
(0.002)^{* *}\end{array}$ \\
\hline Number of Observations & 23,660 & 23,660 & 23,660 & 23,660 \\
\hline $\mathrm{R}$ squared & 0.51 & 0.53 & 0.53 & 0.53 \\
\hline Estimated MPC food stamps & 0.209 & 0.217 & 0.224 & 0.222 \\
\hline Estimated MPC income & 0.086 & 0.054 & 0.051 & 0.057 \\
\hline
\end{tabular}

Notes: Each column presents estimates from a regression of total food expenditures on a dummy variable equal to 1 if the county-year observation had a food stamp program in place by January of that year interacted with the group participation rate. The models differ with respect to the functional form (logs or levels for dependent variable, logs or levels for income). All other control variables and sample selection correspond to specification (4) in Table 3. See the notes to that table for more details. Standard errors are in parentheses and ***, **, and * indicate that the estimates are significant at the $1 \%, 5 \%$ and $10 \%$ levels. Estimates are weighted using the PSID weight and clustered on county. The marginal propensities to consume food are evaluated at mean values for food expenditures and family income among food stamp recipient families. 
Table 10

Impact of Food Stamp Introduction on Family Transfer Income (2005 dollars)

All nonelderly singles and families

(1)

(2)

AFDC income (2005\$)

County FSP Implemented X

773

840

Group participation rate

(968)

(969)

Number of Observations

44,098

44,098

R Squared

0.24

0.24

Other cash welfare (2005\$)

County FSP Implemented X

Group participation rate

Number of Observations

40,299

40,299

R Squared

0.12

0.12

Social Security Income (2005\$)

County FSP Implemented X

Group participation rate

Number of Observations

40,299

40,299

R Squared

0.14

0.14

Demographics

1960 Cty Vars * Linear Time

Year and County Fixed Effects

Per Capita Cty Transfers

$\begin{array}{ll}X & X \\ X & X \\ X & X \\ & X \\ X & X\end{array}$

State $\mathrm{x}$ Linear Time

X

Notes: Each parameter is from a separate regression of the outcome variable on a dummy variable equal to 1 if the county-year observation had a food stamp program in place by January of the year prior to the interview year interacted with a group specific food stamp participation rate. The sample includes nonelderly singles and families from the PSID for interview years 1968-1978. The sample ends in 1978 due to the purchase requirement being eliminated is as of 1979. All other control variables and sample selection correspond to specification (4) in Table 3. See the notes to that table for more details. All outcome variables correspond to annual measures for the year prior to the interview and are expressed in real 2005 dollars. Estimates are weighted using the PSID weight and clustered on county. Standard errors are in parentheses and ***,**, and * indicate that the estimates are significant at the $1 \%, 5 \%$ and $10 \%$ levels. 
Table 11

Impact of Food Stamp Introduction on Labor Supply and Income

\begin{tabular}{|c|c|c|c|c|}
\hline & $\begin{array}{c}\text { Head any } \\
\text { work now } \\
(0 / 1)\end{array}$ & $\begin{array}{c}\text { Head annual } \\
\text { hours }\end{array}$ & $\begin{array}{l}\text { Head annual } \\
\text { earnings } \\
(2005 \$)\end{array}$ & $\begin{array}{l}\text { Log Family } \\
\text { income } \\
(2005 \$)\end{array}$ \\
\hline \multicolumn{5}{|l|}{ All Nonelderly Singles and Families } \\
\hline County FSP Implemented X & -0.179 & -229 & -4716 & 0.017 \\
\hline Group participation rate & $(0.074)^{*}$ & $(156)$ & $(4848)$ & $(0.092)$ \\
\hline Number of Observations & 48,168 & 48,168 & 48,168 & 48,168 \\
\hline R Squared & 0.22 & 0.30 & 0.39 & 0.51 \\
\hline Mean of dependent variable & 0.86 & 1,947 & $\$ 41,742$ & 10.76 \\
\hline \multicolumn{5}{|l|}{$\underline{\text { All Female Headed Families }}$} \\
\hline \multirow[t]{3}{*}{ County FSP Implemented } & -0.066 & -165.1 & -842 & -0.055 \\
\hline & $(0.043)$ & $(69.3)^{* *}$ & $(1001)$ & $(0.040)$ \\
\hline & -0.182 & -456 & -2326 & -0.152 \\
\hline Number of Observations & 7,281 & 7,281 & 7,281 & 7,281 \\
\hline R Squared & 0.38 & 0.42 & 0.49 & 0.50 \\
\hline Mean of dependent variable & 0.58 & 1,068 & $\$ 14,187$ & 10.19 \\
\hline \multicolumn{5}{|l|}{ Nonwhite Female Headed Families } \\
\hline \multirow[t]{3}{*}{ County FSP Implemented } & -0.018 & -136 & -590 & -0.023 \\
\hline & $(0.052)$ & $(71.2)^{*}$ & $(946)$ & $(0.052)$ \\
\hline & -0.033 & -249 & -1083 & -0.042 \\
\hline Number of Observations & 5,465 & 5,465 & 5,465 & 5,465 \\
\hline R Squared & 0.33 & 0.39 & 0.40 & 0.45 \\
\hline Mean of dependent variable & 0.48 & 863 & $\$ 10,008$ & 9.94 \\
\hline Demographics & $\mathrm{X}$ & $\mathrm{X}$ & $\mathrm{X}$ & $\mathrm{X}$ \\
\hline 1960 County Variables * Linear Time & $\mathrm{X}$ & $\mathrm{X}$ & $\mathrm{X}$ & $\mathrm{X}$ \\
\hline Year and County Fixed Effects & $X$ & $\mathrm{X}$ & $\mathrm{X}$ & $X$ \\
\hline Per Capita County Transfers & $\mathrm{X}$ & $\mathrm{X}$ & $\mathrm{X}$ & $\mathrm{X}$ \\
\hline State $\mathrm{x}$ Linear Time & $\mathrm{X}$ & $\mathrm{X}$ & $\mathrm{X}$ & $\mathrm{X}$ \\
\hline
\end{tabular}

Notes: Each parameter is from a separate regression of the outcome variable on a dummy variable equal to 1 if the county-year observation had a food stamp program in place by January of the year prior to the interview year. The policy variable is multiplied by a group specific food stamp participation rate for the results in the first panel, for all nonelderly singles and families. The sample comes from the PSID for interview years 1968-1978. The sample ends in 1978 due to the purchase requirement being eliminated is as of 1979. All other control variables and sample selection correspond to specification (4) in Tables 3-5. All outcome variables correspond to annual measures for the year prior to the interview (except the first column which is at the time of the survey) and all dollar amounts are expressed in real 2005 dollars. Estimates are weighted using the PSID weight and clustered on county. Standard errors are in parentheses and $* * *, * *$, and $*$ indicate that the estimates are significant at the $1 \%, 5 \%$ and $10 \%$ levels. 
Table 12

Impact of Food Stamp Introduction on Labor Supply and Family Income 1960, 1970, 1980 Census STF Analysis

Labor Force Participation Rate

$\begin{array}{cccc}\begin{array}{c}\text { Females 16 } \\ \text { and over }\end{array} & \begin{array}{c}\text { Males 16 } \\ \text { and over }\end{array} & \begin{array}{c}\text { Females with } \\ \text { children }<6\end{array} & \begin{array}{c}\text { Family Income }< \\ \$ 10,000(1979 \$)\end{array}\end{array}$

A. All Races

County FSP Implemented

$-0.003$

0.004

0.009

Number of Observations

$(0.001)$

$(0.001)^{* *}$

$(0.008)$

$(0.002) * * *$

7,898

7,898

7,898

7,898

Mean of dep variable

0.396

0.762

0.337

0.238

B. Nonwhites

County FSP Implemented

0.002

$-0.004$

$\mathrm{n} / \mathrm{a}$

0.027

(0.004)

(0.003)

$(0.006) * * *$

7,443

7,321

7,093

Mean of dep variable

0.457

0.703

0.455

1960 Cty Vars * decade fixed effects

\begin{tabular}{llll}
$X$ & $X$ & $X$ & $X$ \\
$X$ & $X$ & $X$ & $X$ \\
$X$ & $X$ & $X$ & $X$ \\
$X$ & $X$ & $X$ & $X$ \\
\hline
\end{tabular}

Per capital county transfer payments

Decade fixed effects

County fixed effects

Notes: Each parameter is from a separate regression of the outcome variable on a dummy variable equal to 1 if the county-year observation had a food stamp program in place in that year. Data is from 1960-1980 Census county level STF files. Counties in Alaska are dropped because of missing data on food stamp program start date. 1960 county variables include log of population, percent of land in farming, percent of population black, urban, age $<5$, age $>65$ and with income less than $\$ 3,000$ each interacted with decade fixed effects. Per capita county transfer income comes from the BEA REIS and includes measures for public assistance (AFDC, General Assistance), medical care (Medicare, Medicaid, military), and retirement and disability benefits. Estimates are weighted using 1960 county population and are clustered on county. Standard errors are in parentheses and $* * *, * *$, and $*$ indicate that the estimates are significant at the $1 \%, 5 \%$ and $10 \%$ levels. 
Appendix Table 1

Descriptive Statistics for Analysis Using the 1960 City and County Data Book

\begin{tabular}{|c|c|c|c|c|c|}
\hline & $\begin{array}{r}\text { \# nonmissing } \\
\text { obs. }\end{array}$ & Mean & Std Dev & Minimum & Maximum \\
\hline \multicolumn{6}{|l|}{ All Races } \\
\hline LFPR Women $16^{+}$ & 7,898 & 0.396 & 0.114 & 0.051 & 0.798 \\
\hline LFPR Men $16+$ & 7,898 & 0.762 & 0.058 & 0.202 & 0.975 \\
\hline LFPR Women with children $<6$ & 7,898 & 0.337 & 0.341 & 0.000 & 31.329 \\
\hline Family Income $<\$ 10,000(1979 \$)$ & 7,898 & 0.238 & 0.123 & 0.039 & 0.872 \\
\hline Year & 7,898 & 1971 & 8 & 1960 & 1980 \\
\hline County FSP implemented & 7,898 & 0.556 & 0.497 & 0 & 1 \\
\hline County \% black, 1960 & 7,898 & 10.26 & 11.84 & 0 & 83.4 \\
\hline County \% urban, 1960 & 7,898 & 70.23 & 28.73 & 0 & 100 \\
\hline County \% farmland, 1960 & 7,898 & 44.42 & 29.66 & 0 & 239.8 \\
\hline County $\% \leq \$ 3,000,1960$ & 7,898 & 21.31 & 12.94 & 2.1 & 78 \\
\hline County $\%<5$ years, 1960 & 7,898 & 11.36 & 1.53 & 4.7 & 20.4 \\
\hline County $\%>65$ years, 1960 & 7,898 & 9.18 & 2.70 & 1 & 24.9 \\
\hline $\log (1960$ county population $)$ & 7,898 & 12.34 & 1.72 & 6.80 & 15.61 \\
\hline County per cap ret. and dis. payments & 7,898 & 809.2 & 564.4 & 0.0 & 18421.5 \\
\hline County per cap medical payments & 7,898 & 164.2 & 149.2 & 0.0 & 833.2 \\
\hline County per cap cash PA payments & 7,898 & 74.6 & 100.2 & 0.0 & 519.4 \\
\hline \multicolumn{6}{|l|}{ Nonwhites } \\
\hline LFPR Women $16+$ & 7,443 & 0.457 & 0.111 & 0 & 1 \\
\hline LFPR Men $16+$ & 7,321 & 0.703 & 0.083 & 0 & 1 \\
\hline Family Income $<\$ 10,000(1979 \$)$ & 7,093 & 0.455 & 0.186 & 0 & 1 \\
\hline Year & 7,572 & 1972 & 8 & 1960 & 1980 \\
\hline County FSP implemented & 7,572 & 0.638 & 0.481 & 0 & 1 \\
\hline County \% black, 1960 & 7,572 & 19.98 & 15.43 & 0 & 83.4 \\
\hline County \% urban, 1960 & 7,572 & 75.31 & 29.53 & 0 & 100 \\
\hline County \% farmland, 1960 & 7,572 & 38.53 & 28.05 & 0 & 239.8 \\
\hline County $\% \leq \$ 3,000,1960$ & 7,572 & 24.61 & 15.47 & 2.1 & 78 \\
\hline County $\%<5$ years, 1960 & 7,572 & 11.46 & 1.63 & 4.7 & 20.4 \\
\hline County $\%>65$ years, 1960 & 7,572 & 8.60 & 2.37 & 1 & 24.9 \\
\hline $\log (1960$ county population $)$ & 7,572 & 12.73 & 1.82 & 6.82 & 15.61 \\
\hline County per cap ret. and dis. payments & 7,572 & 824.9 & 482.7 & 0.0 & 18421.5 \\
\hline County per cap medical payments & 7,572 & 195.7 & 165.2 & 0.0 & 833.2 \\
\hline County per cap cash PA payments & 7,572 & 109.0 & 132.8 & 0.0 & 519.4 \\
\hline
\end{tabular}

Notes: Data from 1960, 1970, and 1980 county level summary tape files. Counties in Alaska are dropped because of missing data on food stamp program start date. All outcome variables refer to the prior calendar year. Statistics are weighted using the 1960 county population. 
Appendix Table 2: Descriptive Statistics for PSID Expenditure Analysis Sample

\begin{tabular}{|c|c|c|c|c|c|c|c|c|c|c|c|c|}
\hline & \multicolumn{3}{|c|}{$\underline{\text { All Nonelderly Singles and Families }}$} & & $\begin{array}{r}\text { Female } \\
\text { \# nonmissing } \\
\text { obs. }\end{array}$ & Headed $\mathrm{H}$ & iseholds & $\operatorname{Max}$ & \multicolumn{3}{|c|}{ Nonwhite Female Headed Households } & $\begin{array}{l}\text { olds } \\
\text { Max }\end{array}$ \\
\hline FSP participation & 39,623 & 0.066 & 0 & 1 & 6,002 & 0.297 & 0 & 1 & 4,501 & 0.459 & 0 & 1 \\
\hline Real food at home & 39,623 & 6737 & 0 & 35347 & 6,002 & 5902 & 0 & 24131 & 4,501 & 5475 & 0 & 23462 \\
\hline $\log$ (real food at home) & 39,243 & 8.64 & 2.63 & 10.47 & 5,788 & 8.52 & 3.87 & 10.09 & 4,311 & 8.44 & 3.87 & 10.06 \\
\hline Any meals out & 39,623 & 0.766 & 0 & 1 & 6,002 & 0.560 & 0 & 1 & 4,501 & 0.412 & 0 & 1 \\
\hline Real all food & 39,623 & 8179 & 122.8 & 40200 & 6,002 & 7197 & 175 & 35378 & 4,501 & 7017 & 174.9 & 27782 \\
\hline $\log ($ real all food $)$ & 39,623 & 8.86 & 4.8 & 10.6 & 6,002 & 8.75 & 5.2 & 10.5 & 4,501 & 8.71 & 5.2 & 10.2 \\
\hline Food at home / Income & 39,623 & 0.171 & 0 & 0.849 & 6,002 & 0.259 & 0 & 0.849 & 4,501 & 0.301 & 0 & 0.849 \\
\hline All food / Income & 39,623 & 0.179 & 0.003 & 3.620 & 6,002 & 0.287 & 0.009 & 2.140 & 4,501 & 0.351 & 0.009 & 2.140 \\
\hline Real family income & 39,623 & 59643 & 769 & 503346 & 6,002 & 32625 & 824 & 308554 & 4,501 & 24780 & 824 & 123162 \\
\hline Log(real family income) & 39,623 & 10.77 & 6.64 & 13.13 & 6,002 & 10.19 & 6.71 & 12.64 & 4,501 & 9.94 & 6.71 & 11.72 \\
\hline Year & 39,623 & 73.78 & 69 & 78 & 6,002 & 73.94 & 69 & 78 & 4,501 & 73.96 & 69 & 78 \\
\hline County FSP implemented & 39,623 & 0.864 & 0 & 1 & 6,002 & 0.884 & 0 & 1 & 4,501 & 0.893 & 0 & 1 \\
\hline Urban county & 39,623 & 0.605 & 0 & 1 & 6,002 & 0.650 & 0 & 1 & 4,501 & 0.705 & 0 & 1 \\
\hline Female headed household & 39,623 & 0.215 & 0 & 1 & 6,002 & 1 & 1 & 1 & 4,501 & 1 & 1 & 1 \\
\hline Education $<12$ years & 39,623 & 0.327 & 0 & 1 & 6,002 & 0.481 & 0 & 1 & 4,501 & 0.600 & 0 & 1 \\
\hline Education=12years & 39,623 & 0.361 & 0 & 1 & 6,002 & 0.380 & 0 & 1 & 4,501 & 0.311 & 0 & 1 \\
\hline Education $>12$ years & 39,623 & 0.312 & 0 & 1 & 6,002 & 0.140 & 0 & 1 & 4,501 & 0.089 & 0 & 1 \\
\hline White & 39,623 & 0.856 & 0 & 1 & 6,002 & 0.635 & 0 & 1 & 4,501 & 0 & 0 & 0 \\
\hline Number of children & 39,623 & 1.27 & 0 & 13 & 6,002 & 2.12 & 1 & 11 & 4,501 & 2.54 & 1 & 11 \\
\hline Number of adults & 39,623 & 1.97 & 1 & 14 & 6,002 & 1.47 & 1 & 8 & 4,501 & 1.63 & 1 & 8 \\
\hline State unemployment rate & 39,623 & 6.19 & 2 & 12.5 & 6,002 & 6.33 & 2 & 12.5 & 4,501 & 6.32 & 2 & 12.5 \\
\hline County \% black, 1960 & 39,623 & 9.62 & 0 & 81.3 & 6,002 & 12.30 & 0 & 62.1 & 4,501 & 19.60 & 0.1 & 62.1 \\
\hline County \% urban, 1960 & 39,623 & 70.03 & 0 & 100 & 6,002 & 74.59 & 0 & 100 & 4,501 & 82.17 & 0 & 100 \\
\hline County \% farmland, 1960 & 39,623 & 44.89 & 0 & 239.8 & 6,002 & 41.78 & 0 & 126.6 & 4,501 & 36.51 & 0 & 116.2 \\
\hline County $\% \leq \$ 3,000,1960$ & 39,623 & 20.92 & 5.5 & 74.4 & 6,002 & 20.51 & 5.5 & 68 & 4,501 & 21.40 & 5.5 & 68 \\
\hline County $\%<5$ years, 1960 & 39,623 & 11.26 & 5.6 & 18.2 & 6,002 & 11.22 & 6.7 & 18.2 & 4,501 & 11.26 & 7.4 & 15.1 \\
\hline County $\%>65$ years, 1960 & 39,623 & 9.27 & 1 & 24.9 & 6,002 & 9.22 & 2.8 & 24.9 & 4,501 & 8.94 & 2.8 & 24.9 \\
\hline $\log (1960$ county population $)$ & 39,623 & 12.28 & 7.72 & 15.61 & 6,002 & 12.62 & 7.72 & 15.61 & 4,501 & 13.20 & 8.74 & 15.61 \\
\hline County per cap ret. and dis. payments & 39,623 & 994.2 & 112.4 & 2969.3 & 6,002 & 1013.9 & 172.8 & 2609.4 & 4,501 & 986.8 & 220.2 & 2609.4 \\
\hline County per cap medical payments & 39,623 & 226.6 & 35.0 & 690.8 & 6,002 & 237.3 & 37.0 & 686.7 & 4,501 & 252.7 & 65.6 & 686.7 \\
\hline County per cap cash PA payments & 39,623 & 226.7 & 0.0 & 1086.8 & 6,002 & 272.2 & 15.6 & 1086.8 & 4,501 & 330.2 & 20.0 & 1086.8 \\
\hline
\end{tabular}

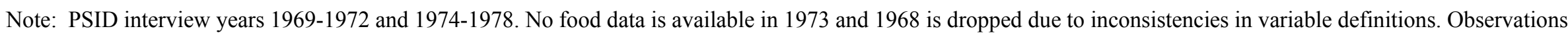
from Alaska are dropped because of missing data on food stamp program start date and observations with unusual expenditure values are dropped (annual food

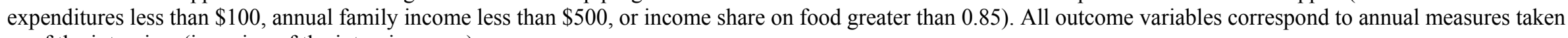
as of the interview (in spring of the interview year). 
Appendix Table 3: Descriptive Statistics for PSID Labor Supply Analysis Sample

\begin{tabular}{|c|c|c|c|c|c|c|c|c|c|c|c|c|}
\hline & $\begin{array}{r}\text { All Noneld } \\
\begin{array}{r}\text { \# nonmissing } \\
\text { obs. }\end{array}\end{array}$ & ly Single & d Fam & Max & $\begin{array}{r}\text { Female } \\
\text { \# nonmissing } \\
\text { obs. }\end{array}$ & Headed $\mathrm{H}$ & eholds & $\operatorname{Max}$ & $\begin{array}{r}\text { Nonwhite F } \\
\text { \# nonmissing } \\
\text { obs. }\end{array}$ & ale Hea & House & olds \\
\hline Real AFDC income & 44,098 & 339 & 0 & 51080 & 6,674 & 2703 & 0 & 39054 & 5,014 & 4498 & 0 & 39054 \\
\hline Real Soc security income & 40,299 & 650 & 0 & 43400 & 6,062 & 2184 & 0 & 41453 & 4,563 & 1699 & 0 & 41453 \\
\hline Real other welfare income & 40,299 & 153 & 0 & 40039 & 6,062 & 779 & 0 & 35122 & 4,563 & 1273 & 0 & 32099 \\
\hline Head work last week & 48,168 & 0.857 & 0 & 1 & 7,281 & 0.583 & 0 & 1 & 5,465 & 0.478 & 0 & 1 \\
\hline Head work last year & 48,168 & 0.926 & 0 & 1 & 7,281 & 0.707 & 0 & 1 & 5,465 & 0.615 & 0 & 1 \\
\hline Head annual hours & 48,168 & 1947 & 0 & 5824 & 7,281 & 1068 & 0 & 4628 & 5,465 & 863 & 0 & 4628 \\
\hline Head real annual earnings & 48,168 & 41742 & 0 & 503346 & 7,281 & 14187 & 0 & 117854 & 5,465 & 10008 & 0 & 75516 \\
\hline Real family income & 48,168 & 59228 & 748 & 503346 & 7,281 & 32683 & 824 & 308554 & 5,465 & 24901 & 824 & 130699 \\
\hline $\log ($ real family income $)$ & 48,168 & 10.76 & 6.62 & 13.13 & 7,281 & 10.19 & 6.71 & 12.64 & 5,465 & 9.94 & 6.71 & 11.78 \\
\hline Year & 48,168 & 73.18 & 68 & 78 & 7,281 & 73.42 & 68 & 78 & 5,465 & 73.42 & 68 & 78 \\
\hline County FSP implemented & 48,168 & 0.824 & 0 & 1 & 7,281 & 0.856 & 0 & 1 & 5,465 & 0.867 & 0 & 1 \\
\hline Urban county & 48,168 & 0.622 & 0 & 1 & 7,281 & 0.670 & 0 & 1 & 5,465 & 0.724 & 0 & 1 \\
\hline Female headed household & 48,168 & 0 & 0 & 1 & 7,281 & 1 & 1 & 1 & 5,465 & 1 & 1 & 1 \\
\hline Education $<12$ years & 48,168 & 0.335 & 0 & 1 & 7,281 & 0.482 & 0 & 1 & 5,465 & 0.609 & 0 & 1 \\
\hline Education $=12$ years & 48,168 & 0.353 & 0 & 1 & 7,281 & 0.376 & 0 & 1 & 5,465 & 0.304 & 0 & 1 \\
\hline Education $>12$ years & 48,168 & 0.312 & 0 & 1 & 7,281 & 0.142 & 0 & 1 & 5,465 & 0.087 & 0 & 1 \\
\hline White & 48,168 & 0.857 & 0 & 1 & 7,281 & 0.634 & 0 & 1 & 5,465 & 0.000 & 0 & 0 \\
\hline Number of children & 48,168 & 1.29 & 0 & 13 & 7,281 & 2.15 & 1 & 11 & 5,465 & 2.57 & 1 & 11 \\
\hline Number of adults & 48,168 & 1.98 & 1 & 14 & 7,281 & 1.48 & 1 & 8 & 5,465 & 1.62 & 1 & 8 \\
\hline State unemployment rate & 48,168 & 5.82 & 2 & 12.5 & 7,281 & 6.00 & 2 & 12.5 & 5,465 & 5.99 & 2 & 12.5 \\
\hline County \% black, 1960 & 48,168 & 9.7 & 0 & 81.3 & 7,281 & 12.4 & 0 & 62.1 & 5,465 & 19.7 & 0.1 & 62.1 \\
\hline County \% urban, 1960 & 48,168 & 70.2 & 0 & 100 & 7,281 & 75.0 & 0 & 100 & 5,465 & 82.0 & 0 & 100 \\
\hline County \% farmland, 1960 & 48,168 & 44.8 & 0 & 239.8 & 7,281 & 41.4 & 0 & 126.6 & 5,465 & 36.4 & 0 & 116.2 \\
\hline County $\% \leq \$ 3,000,1960$ & 48,168 & 20.9 & 5.5 & 74.4 & 7,281 & 20.5 & 5.5 & 68 & 5,465 & 21.5 & 5.5 & 68 \\
\hline County $\%<5$ years, 1960 & 48,168 & 11.2 & 5.6 & 18.2 & 7,281 & 11.2 & 6.7 & 18.2 & 5,465 & 11.3 & 7.4 & 15.1 \\
\hline County $\%>65$ years, 1960 & 48,168 & 9.3 & 1 & 24.9 & 7,281 & 9.2 & 2.8 & 24.9 & 5,465 & 9.0 & 2.8 & 24.9 \\
\hline $\log (1960$ county population $)$ & 48,168 & 12.29 & 7.72 & 15.61 & 7,281 & 12.65 & 7.72 & 15.61 & 5,465 & 13.19 & 8.74 & 15.61 \\
\hline County per cap ret. and dis. payments & 48,168 & 983.0 & 0 & 23532 & 7,281 & 1025.1 & 0 & 23532 & 5,465 & 985.2 & 0 & 4539 \\
\hline County per cap medical payments & 48,168 & 219.0 & 0 & 6647 & 7,281 & 236.2 & 0 & 6647 & 5,465 & 246.4 & 0 & 1282 \\
\hline County per cap cash PA payments & 48,168 & 225.0 & 0 & 14071 & 7,281 & 283.9 & 0 & 14071 & 5,465 & 332.7 & 0 & 2714 \\
\hline
\end{tabular}

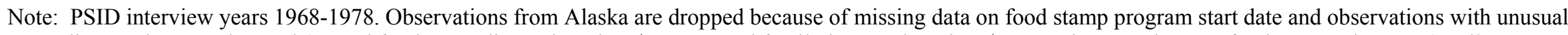

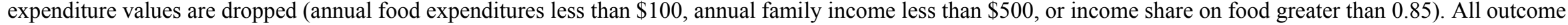
variables (except head working last week) correspond to annual measures taken as of the interview (in spring of the interview year). 